\title{
Oscillating and unidirectional sliding wear behaviour of cold sprayed Ti-6Al-4V coating on Ti-6Al-4V substrate
}

\author{
P. Sirvent ${ }^{\mathrm{a}, 1^{*}}$, M.A. Garrido ${ }^{\mathrm{a}}, \mathrm{S}$. Lozano-Pérez $^{\mathrm{b}}$, P. Poza $^{\mathrm{a}}$
}

a DIMME - Durability and Mechanical Integrity of Structural Materials, Escuela Superior de Ciencias Experimentales y Tecnología, Universidad Rey Juan Carlos, C/Tulipán s/n, 28933 Móstoles, Madrid, Spain.

${ }^{\mathrm{b}}$ Department of Materials, University of Oxford, 16 Parks Road, Oxford OX1 3PH, United Kingdom.

\section{Abstract}

Ti-6Al-4V components are widely used in the aircrafts engine or airframe parts, as landing gears or wing boxes, where the wear by unidirectional sliding or oscillating relative motion is one of the most recurrent damage processes. Recently, the deposition by Cold-Spray (CS) has been revealed as a promising alternative to repair these damaged components, increasing their useful time and decreasing the maintenance costs. Consequently, the wear resistance of the coatings could be improved by optimizing the CS processing parameters. In this work, oscillating and unidirectional sliding wear tests were planned to determine the wear resistance of Ti-6Al-4V coatings deposited onto substrates of the same Ti alloy by CS. The coatings were sprayed using two different values for two of the main spraying parameters. First, values of $800{ }^{\circ} \mathrm{C}$ and 40 bars were used for the process gas temperature and pressure, respectively, which are widely used spray conditions by researchers; and secondly, values of $1100^{\circ} \mathrm{C}$ and 50 bar were used for both parameters, respectively. Unidirectional sliding and oscillating wear tests were performed and the effect of the testing temperature was studied. The

\footnotetext{
${ }^{1}$ Institute of Construction Science Eduardo Torroja - CSIC, C/ Serrano Galvache, 4, 28033 Madrid, Spain

*corresponding author: paloma.sirvent@ietcc.csic.es
} 
main wear mechanisms in room temperature (RT) were abrasion and adhesion, while oxidation was also distinguished during the high temperature tests. In addition, the wear processes were more severe during the unidirectional sliding tests as compared to the oscillating tests. The results showed that the coatings deposited using the first spraying conditions presented a poor wear resistance as compared to the substrate and thus they are not adequate for repairing purposes. However, the coatings deposited using higher values of gas temperature and pressure showed a comparable, or even better, wear resistance to that of the substrate under oscillating movement.

\section{Introduction:}

The design and selection of materials in the aeronautical industry are determined by two critical factors: weight and cost. Both are related. Less weight means lower fuel consumption and therefore lower cost per passenger and more flight autonomy. That is why Ti-6Al-4V alloy is one of the most used alloys as part of the different aircraft components [1]. Ti alloys present a combination of very attractive specific properties for the aeronautical industry [2]. Ti components constitute a $15 \mathrm{wt} . \%$ of the most used materials in airframes, while they comprise around a $25 \mathrm{wt} . \%$ in the engine. Fan blades, low-pressure compressor parts or plug and nozzle assemblies are examples of Ti alloys components used in the engine [3]. Further examples of Ti aeronautical components include landing gears, wing boxes or stiffeners. Consequently, several aircraft $\mathrm{Ti}$ components are going to be subjected to relative movement. This can be oscillating, unidirectional sliding or both simultaneously. This circumstance causes that one of the recurrent failures of these components is due to damage by wear. Due to the strict safety regulations in the aeronautical industry, it is a common practice to replace any damaged component. This comes into a high maintenance cost. However, an alternative could be 
to repair the damaged components, increasing their service life and reducing the waste $[4]$.

One of the most common repair strategies involves the application of coatings on the damaged surfaces. In this way, it is necessary to ensure that the deposited coating has similar properties to those of the bulk material. One of the most promising coatings spraying process for aeronautical light alloys is the cold spray (CS) technique. In the CS process, the coating is developed by the stacking of solid-state particles. The powder is projected at a temperature below its melting point and at high velocities, so that the coating is deposited due to the severe plastic deformation at the impact with the substrate [5]. Therefore, CS is a solid-state process and thus, chemical or microstructural changes are avoided during the coatings deposition and high dense coatings can be obtained [6]. Additionally, due to the minimal substrate-coating thermal difference, the residual stresses induced in the coating are minimized. CS is therefore advantageous to deposit light alloy coatings as compared to other high thermal spray technologies, as high velocity oxy-fuel or plasma spray [7]. The high deposition temperature of these techniques may cause oxidation or compositional changes during spraying, or the development of high residual stresses what means a restriction to the coatings thickness.

This work is focussed on the repair of Ti components used in the aircrafts engines or airframe parts (such as landing gears) where frictional forces merge due to the unidirectional sliding and oscillating contacts between these components and steel counterparts. CS technique was selected to deposit Ti-6Al-4V coatings for the repairing the bulk Ti-6Al-4V. For this reason, a similar Ti alloy was used as substrate. The wear behaviour of the bulk Ti-6Al-4V has been extensively studied. Ti is usually classified as a poor wear resistant material due to its low resistance to plastic shearing and its low 
work-hardenability as well as due to the low protective oxides generated during sliding [8-10]. This result has been explained due to the weak adherence with the substrate and easy fragmentation of the oxides. On the contrary, some studies have reported a protective effect against wear exerted by the tribo-oxides during sliding wear of Ti-6Al4V at high temperature [11-13]. The tribo-layers containing a higher degree of oxides are reported to present a higher wear resistance because of the hardness increment at the surface sample. In addition, the protective oxide layers are denser and well adhered than the oxides generated at lower temperatures. These oxides prevent metal-metal adhesion and therefore, the wear rate and coefficient of friction are reduced.

Up to the date, little work can be found about CS Ti coatings wear behaviour because of the relatively recent development of this technology. Moreover, the available papers in literature are basically related to dry sliding wear tests using a ball on disc configuration and performance at room temperature (RT) conditions. Khun et al. [14] deposited Ti coatings onto Ti-6Al-4V substrates by CS. They showed that the wear behaviour of CS Ti coatings was improved regarding to the bulk alloy. In addition, it was shown that denser coatings presented a better wear behaviour. On the other hand, Alidokht et al. [15] examined the role of third bodies in friction and wear of CS Ti coatings deposited under the traditional spraying conditions by conducting dry sliding wear experiments. They concluded that the tribofilms generated on the surface of the worn Ti coatings provided no protection against wear. Moreover, Astarita et al. [16] published a paper about reciprocating wear on CS Ti coatings with a ball-on-flat configuration which demonstrates the wear properties improvement as compared to the AA2024 alloy, which was the substrate used for spraying. To the author's knowledge, only a short paper [17] has been recently published with preliminary results about oscillating wear using flat-on-flat configuration on CS Ti-6Al-4V coatings. In addition, high temperature 
tests are also performed on that work [17], but no other studies have been found reporting high temperature wear tests on CS Ti-6Al-4V coatings.

However, as studies have shown, the optimization of CS parameters for Ti coatings should also be evaluated in order to improve the wear resistance of the CS Ti coatings. Several attempts have already been reported. Khun et al. [18] analysed the effect of the working gas on the wear behaviour of Ti-6Al-4V deposited by CS. They tested samples sprayed using helium and nitrogen as working gases. They concluded that Ti-6Al-V coatings deposited with helium gas have higher hardness and wear resistance. However, helium is expensive, which reduces the profitability of carrying out maintenance operations on damaged aeronautical components. The alternative is to use nitrogen as propellant gas, but the spraying parameters need to be optimized to obtain reliable coldsprayed coatings. The higher density of this gas requires a higher energy input to accelerate the particle and gas jet. However, the increase in particle velocity may be restrained by the limited range of parameters of the equipment or other setup problems, such as noozle clogging [5].

The aim of this work is to analyse the effect of using higher nitrogen gas temperature and pressure than those generally applied in literature for CS Ti-6Al-4V coatings, on the oscillating wear resistance of CS Ti-6Al-4V coatings, deposited on substrates of the same alloy. The microstructural and mechanical properties of these coatings are described in our previous work [19] while the wear behaviour was evaluated here. For comparison, the study was extended to the analysis of the unidirectional sliding wear behaviour of these Ti-6Al-4V coatings. The wear behaviour of the coatings was evaluated by comparing their performance against that of the substrate, which was the material being repaired. Additionally, the wear mechanisms were identified and the influence of the testing temperature on the wear processes of the coatings was analysed. 


\section{Materials and methods:}

\subsection{Materials:}

CS Ti-6Al-4V coatings were deposited on substrates of the same alloy. The initial materials for deposition as well as the spraying conditions were the same as that reported in our previous study on the microstructure and mechanical properties of the fabricated coatings [19]. The feedstock powder was supplied by LPW (United Kingdom) and it was fabricated by gas atomization. The powder characteristics were reported in the previous work [19]. The particles were spherical, with a size of $(-25+15)$ $\mu \mathrm{m}$ and they presented a martensitic microstructure. Commercial plates of the Ti-6Al$4 \mathrm{~V}$ alloy (aeronautical grade) were used as substrates. The plate's surfaces were ground using SiC paper, 120 grit, before CS deposition.

An Impact 5/11 CS system was used to fabricate the coatings using nitrogen as process gas and spraying with a water-cooled SiC nozzle. The coatings were fabricated at "The Welding Institute” (TWI, United Kingdom). Two different coatings were deposited using the sets of parameters which are detailed in Table 1. The deposition method of these coatings was the same as that reported elsewhere [19]. The fabrication parameters were the same for both coatings excluding the process gas temperature and pressure. Coating was first sprayed using a process gas temperature of $800^{\circ} \mathrm{C}$ and a pressure of 40 bar, which are considered as CS Ti spray conditions widely used by researchers. The process gas temperature and pressure were increased up to $1100{ }^{\circ} \mathrm{C}$ and 50 bar, respectively, in a second coating in order to compare its performance with the first one. The coatings sprayed with a process gas temperature of $800{ }^{\circ} \mathrm{C}$ and $1100{ }^{\circ} \mathrm{C}$ are referred as Ti64-800 and Ti64-1100, respectively, in this work. 
A detailed description of the CS Ti-6Al-4V coatings microstructure and their mechanical properties have been reported in our previous wok [19]. The coatings were constituted by splats and they presented a martensitic $\alpha$ '-Ti microstructure, similar to that of the feedstock powder. On the other hand, the substrate presented an equiaxed microstructure of $\alpha$-Ti grains and retained $\beta$-Ti phase at the grain boundaries. The coating processed at the highest process gas temperature and pressure (Ti64-1100) presented a lower porosity and a higher hardness as compared with the other coating (Ti64-800). The mean roughness $\left(\mathrm{R}_{\mathrm{a}}\right)$, the hardness $(\mathrm{H})$ and the elastic modulus $(\mathrm{E})$ of the substrate and both of the CS coatings are reported in Table 2. The thickness and porosity of the coatings are also included.

Table 1. CS process parameters for the Ti64-800 and Ti64-1100 coatings deposition.

\begin{tabular}{lll}
\hline \multirow{2}{*}{ CS parameters } & Value & \\
\cline { 2 - 3 } & Ti64-800 & Ti64-1100 \\
\hline Process Gas Temperature & $800^{\circ} \mathrm{C}$ & $1100^{\circ} \mathrm{C}$ \\
Process Gas Pressure & $40 \mathrm{bar}$ & $50 \mathrm{bar}$ \\
Spraying distance & $50 \mathrm{~mm}$ & $50 \mathrm{~mm}$ \\
Traverse speed & $500 \mathrm{~mm} / \mathrm{s}$ & $500 \mathrm{~mm} / \mathrm{s}$ \\
Number of Passes & 4 & 4 \\
Track spacing & $1 \mathrm{~mm}$ & $1 \mathrm{~mm}$ \\
Spraying angle & $90^{\circ}$ & $90^{\circ}$ \\
Powder feeder wheel rotational speed & $3 \mathrm{rpm}$ & $3 \mathrm{rpm}$ \\
\hline
\end{tabular}

Table 2 Summary of the CS coatings and the substrate properties as reported by Garrido et al [19]. Elastic modulus (E) and hardness $(\mathrm{H})$ measurements were performed by nanoindentation at room temperature.

\begin{tabular}{llllll}
\hline Material & $\begin{array}{l}\text { Roughness, } \\
\mathbf{R}_{\mathbf{a}}(\boldsymbol{\mu m})\end{array}$ & $\begin{array}{l}\text { Thickness } \\
(\boldsymbol{\mu m})\end{array}$ & Porosity $(\%)$ & E (GPa) & H(GPa) \\
\hline Substrate & $0.46 \pm 0.04$ & - & - & $110.8 \pm 3.6$ & $3.61 \pm 0.09$ \\
Ti64-800 & $10.10 \pm 0.94$ & $725 \pm 74$ & $18.1 \pm 1.3$ & $99.3 \pm 5.9$ & $3.53 \pm 0.26$ \\
Ti64-1100 & $7.92 \pm 0.51$ & $684 \pm 27$ & $3.83 \pm 0.39$ & $104.6 \pm 3.1$ & $4.08 \pm 0.31$ \\
\hline
\end{tabular}




\subsection{Methods}

\subsubsection{Wear tests}

Oscillating wear experiments were conducted on the CS Ti-6Al-4V coatings against a bearing steel counterbody (100Cr6) to study their wear response under oscillating tangential movements. This motion is typically found at joints between aircraft components such as in landing gears, engine compressor blades, bolts or in rotor head of helicopters. The use of the steel counterbody was selected because Ti may be in contact with this material in some aircraft parts as for example in landing gears. Unidirectional sliding wear tests were also conducted as a reference because the use of this type of test is more extended. In addition, the same experiments were done on samples of the substrate in order to compare the wear behaviour of the coatings with regard to the bulk Ti-6Al-4V alloy, which is the material being repaired.

A Wazau TRM1000 tribometer was used to perform the unidirectional sliding experiments in accordance with the ASTM G99 standard [20]. This is a pin on disc equipment in which a flat pin, located at a stationary rig, is put in contact with a rotating flat disc. The position of the pin was fixed at a distance of $26 \mathrm{~mm}$ with regard to the counterbody disc geometrical centre. The CS Ti-6Al-4V coatings and the substrate were used as pins, respectively, while the bearing steel was used as the disc. The coatings were tested in its as-sprayed state, which means that they presented the above mentioned surface roughness reported in Table 2 . The pins were prepared with a surface section of $2.5 \times 6 \mathrm{~mm}$ and they were cleaned with acetone by immersion in an ultrasound bath during $10 \mathrm{~min}$ before the tests. They were also weighted before and after the tests. The steel discs consisted of cylindrical plates measuring $60 \mathrm{~mm}$ in 
diameter and $15 \mathrm{~cm}$ in thickness and they presented a hardness of $760 \pm 17 \mathrm{HV}$ and a surface roughness of $\mathrm{R}_{\mathrm{a}}=0.62 \pm 0.07 \mu \mathrm{m}$. They were cleaned with water and soap and then with acetone before the tests.

The parameters which can be adjusted in the tests are the normal load, the sliding speed and the temperature. A normal load is applied to the system through a lever arm. Thus, the normal pressure on the pin is calculated as the ratio of the applied normal load to the surface area of the pin. The disc sliding speed is controlled through a drive spindle. The high temperature experiments up to $450{ }^{\circ} \mathrm{C}$ were done by attaching a furnace to the equipment so that the pin and the counterbody were enclosed inside it during the whole test. The temperature inside the furnace was measured through a thermocouple installed at the pin rig. After installing the furnace, the system was heated up to $450{ }^{\circ} \mathrm{C}$ and it was fixed until the end of the experiment. The high temperature tests were started after reaching a steady state environmental temperature at $450{ }^{\circ} \mathrm{C}$. However, it should be noted that the temperature at the contact is not stable during the test due to frictional heating.

The equipment records the temperature, the measure of the linear displacement of the pin from the position of the initial contact with the counterbody (h) and the applied torque to the spindle as a function of time during the tests. $\mathrm{h}$ is acquired from the measurement of a linear variable differential transformer. The applied torque to the spindle is used to obtain the tangential applied force and thus, to calculate the coefficient of friction (COF).The COF was continuously recorded during the test. Figure 1 shows representative examples of the COF evolution. The COF value reported here was calculated as the mean value the steady state range of data. The wear rate $(\delta \mathrm{m})$ was calculated as the ratio of the weight loss of the pins during the tests $(\Delta \mathrm{m})$ by the test time $(\Delta \mathrm{t})$ : 


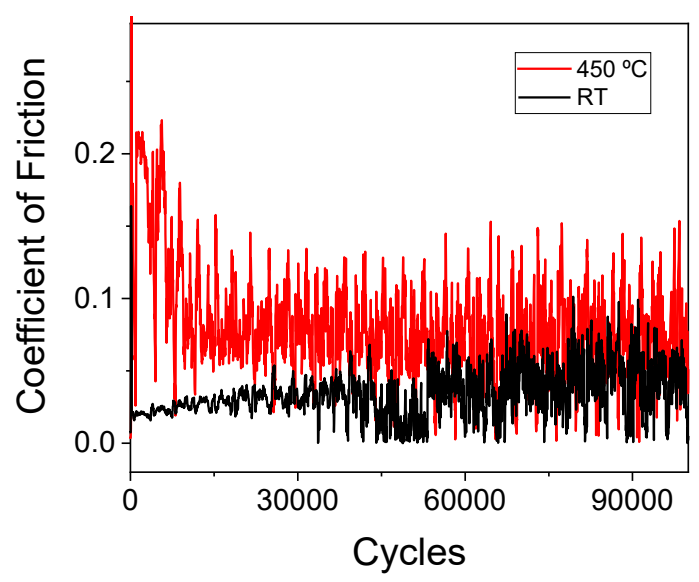

Figure 1 Representative examples of the coefficient of friction evolution as a function of the number of cycles corresponding to oscillating experiments conducted on the Ti64800 coating at $\mathrm{RT}$ and at $450{ }^{\circ} \mathrm{C}$.

a)

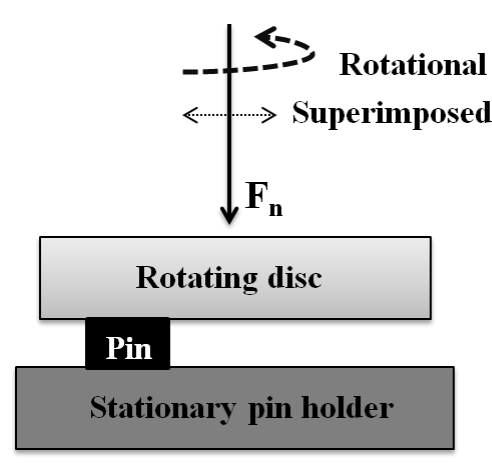

b)

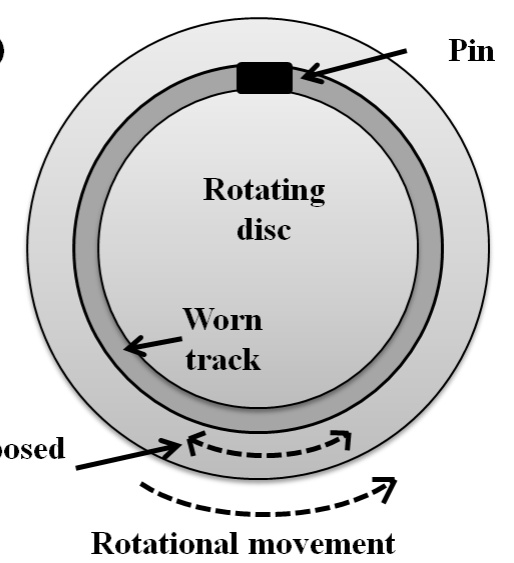

Figure 2 Schematic representation of the pin on disc configuration showing a) a crosssectional view and b) the plan view of the system. The oscillating type of movement is indicated in the figure by the combination of the rotational and the superimposed vibration motions.

The Wazau TRM 1000 tribometer was also used to evaluate the wear rate under oscillating conditions. To simulate the oscillating movement, the most suitable type of motion allowed by the tribometer, was a combined movement of rotation and vibration 
of the disc as illustrated in Figure 2. The parameters that have been chosen as variables in this type of motion were the normal load, the amplitude of oscillation and the temperature. The rotational speed was set at the lower available value to minimize its contribution, and the frequency of the oscillating movement was fixed at $40 \mathrm{~Hz}$. The experimental information which was collected during these tests was the same as that collected from the unidirectional sliding experiments which has been described above.

Table 3 shows a summary of the experimental parameters used for conducting the tests. The parameters were selected considering the more severe conditions to which $\mathrm{Ti}$ aircraft components could be subjected in operation. The experiments were done with both types of motion: unidirectional sliding and oscillating. Two replicas were conducted for each one of the tests. The number of cycles in the oscillating tests was set at 100000 , what was in accordance to the number of cycles used in other works related with fretting wear in aircraft components $[21,22]$. However, the test was stopped if the wear depth exceeded a value of $600 \mu \mathrm{m}$. This limit was set to ensure that the wear was not surpassing the coatings thickness.

Table 3 Test parameters values of the two kind of wear experiments: unidirectional sliding and the oscillating wear experiments (slow rotation of the disc with a superimposed vibration).

\section{Pin on disc tests}

\begin{tabular}{llllll}
\hline $\begin{array}{l}\text { Type of } \\
\text { motion }\end{array}$ & $\begin{array}{l}\text { Temperature } \\
\left({ }^{\circ} \mathbf{C}\right)\end{array}$ & $\begin{array}{l}\text { Sliding } \\
\text { Velocity } \\
(\mathbf{m} / \mathbf{s})\end{array}$ & $\begin{array}{l}\text { Normal } \\
\text { Pressure } \\
(\mathbf{M P a})\end{array}$ & $\begin{array}{l}\text { Oscillation } \\
\text { Amplitude } \\
(\boldsymbol{\mu m})\end{array}$ & $\begin{array}{l}\text { Oscillation } \\
\text { Frequency } \\
(\mathbf{H z})\end{array}$ \\
\hline $\begin{array}{l}\text { Unidirectional } \\
\text { Sliding }\end{array}$ & 25 & 0.26 & 30 & - & - \\
\cline { 2 - 6 } & 450 & 0.26 & 30 & - & - \\
\hline Rotation+ & 25 & 0.0026 & 30 & 596 & 40 \\
Vibration & 450 & 0.0026 & 30 & 596 & 40 \\
\hline
\end{tabular}




\subsubsection{Wear mechanisms evaluation}

The wear mechanisms were evaluated by analysing the microstructure of the worn surfaces and the transversal section of the near surface of the pins. This characterization was conducted with a scanning electron microscope (SEM, Hitachi S3400N) and an energy dispersive X-ray detector (EDX, Bruker XFlash 5010) which was attached to the microscope. Secondary electron (SE) and backscattered electron (BSE) images were used for the study. The pins were cleaned within an ultrasound bath of alcohol before the SEM investigation of the worn surfaces. The sliding direction has been indicated by black arrows in the micrographs corresponding to worn surfaces in this manuscript. Samples of the transversal cross sections of the worn pins were obtained by performing a cut perpendicular to their surface with a diamond cut-off wheel. The sliding direction is therefore perpendicular to the shown plane in all the cross-sectional images in this manuscript. These sample cuts were metallographically prepared. They were first mounted in a low stiffness resin and then, they were grinded and polished using a final polishing suspension of colloidal silica $(0.04 \mu \mathrm{m})(\mathrm{OP}-\mathrm{U})$. Moreover, some selected worn samples were also investigated at the top surface of their transversal cross sections using transmission electron microscopy (TEM). This later analysis was conducted with a JEOL JEM-2100 TEM operated at $200 \mathrm{keV}$. The TEM sample preparation was done using the NVision 40 and the Auriga Zeiss focused ion beam (FIB)/SEM systems. The TEM study was done using imaging techniques as bright field (BF) and dark field (DF), EDX microanalysis and selected area electron diffraction patterns (SADPs).

FIB sample preparation consisted in the extraction of specimens by ion milling the material around and underneath the region of the sample to be lifted-out. Prior to commencing the milling, a platinum rectangular strap $(\sim 25 \mu \mathrm{m} \times 2.5 \mu \mathrm{m} \times 2.5 \mu \mathrm{m})$ was deposited on the region of interest to protect the specimen. After that, trenches were 
milled in the material around the region of interest, expect on one side, using ion beam current around $10 \mathrm{nA}$. The sample was also tilted to remove the material at the region underneath the sample by striking with the ions. The final size of the FIB sample allowed to examine the microstructure from the top surface of the worn sample up to about $5 \mu \mathrm{m}$ in depth.

Once the milling was completed, the specimen was lifted-up. For this purpose, the sample was attached to a micromanipulator needle using platinum deposition. The region of the material that was holding the specimen to the sample was then milled to complete the lift-up. Following this, the specimen was attached to a copper grid using platinum deposition and the needle was detached from the sample by ion milling. Finally, the final thinning of the specimen was conducted by milling at both sides of the specimen until a thickness of $<100 \mathrm{~nm}$ was achieved. The milling current (from $\sim 0.5$ $\mathrm{nA}$ to $\sim 100 \mathrm{pA}$ ) and energy (from $20 \mathrm{kV}$ to $5 \mathrm{kV}$ ) were decreased as the thickness of the sample was being reduced to obtain a smooth surface.

\section{Results and discussion:}

\subsection{COF and wear rate results}
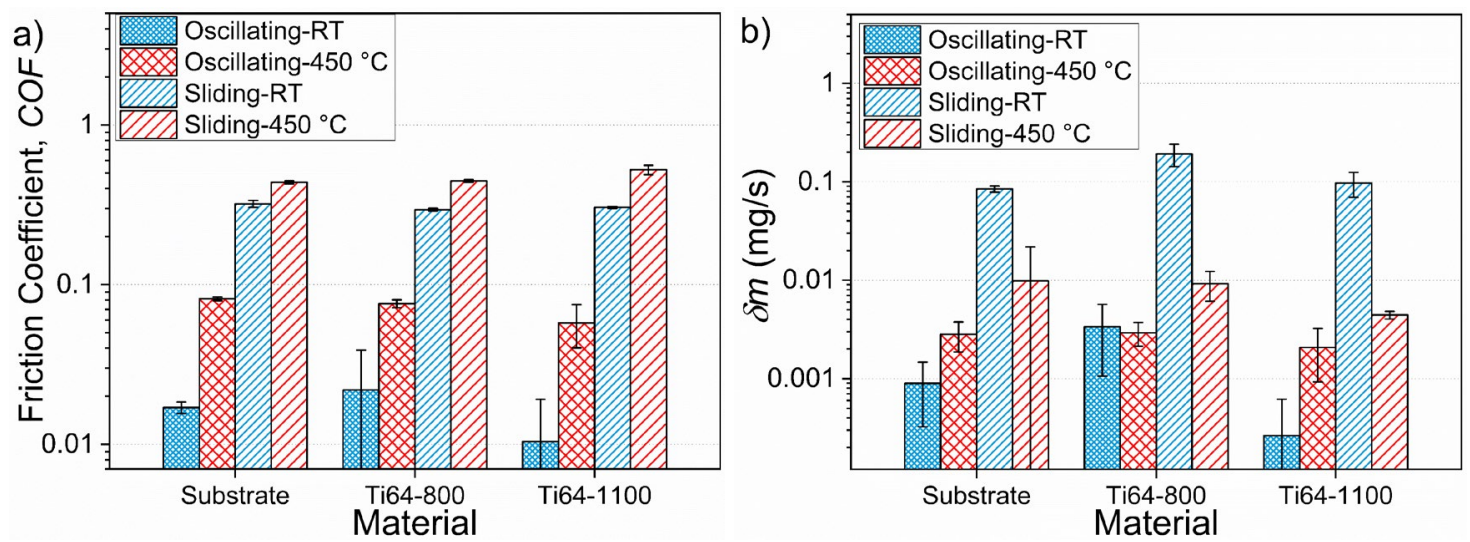
Figure 3 Comparative graphs of a) the COF results, b) the wear rates calculated from the weight loss measurements of the pins, $\delta \mathrm{m}$, corresponding to the oscillating and unidirectional sliding wear tests conducted on the CS coatings and on the substrate.

Figure 3 shows the $\mathrm{COF}$ and the wear rate, $\delta \mathrm{m}$, results that were obtained from the oscillating and the unidirectional sliding experiments on the substrate and both studied coatings. The COF values of the oscillating tests were clearly different from those of the unidirectional sliding tests (Figure 3a). The COF obtained from the oscillating experiments was around 0.015 for all the tested materials during the RT tests and $\sim 0.1$ when testing at $450{ }^{\circ} \mathrm{C}$. On the other hand, in the unidirectional sliding experiments, the COF was $\sim 0.3$ and $\sim 0.45$ for the tests conducted at RT and $450{ }^{\circ} \mathrm{C}$, respectively. The increase in temperature was shown to increase the COF value in both movement conditions. Moreover, it was noted that the increments of COF with temperature were shown to be greater in the case of the oscillating experiments. This result was attributed to the different contributions of each wear mechanism and debris on the different wear processes.

Regarding to the wear rate $(\delta \mathrm{m})$ results, the tests conducted at unidirectional sliding and RT conditions presented significantly higher wear rates as compared with the tests performed at $450{ }^{\circ} \mathrm{C}$. On the other hand, the effect of the temperature on the wear rates of the oscillating experiments was not clear. The wear rates were shown to be lower for the oscillating experiments at RT on the substrate and the Ti64-1100 coating, which was the opposite trend as compared to that observed in the unidirectional sliding experiments. Regarding to the Ti64-800 coating, the wear rates under oscillating conditions were similar for both testing temperatures. 
The comparison between the wear rates under sliding movement of the different materials revealed that the Ti64-800 and Ti64-1100 coatings were shown to fail under unidirectional sliding conditions at RT. Although, their wear resistance at $450^{\circ} \mathrm{C}$ were greater than that showed by the substrate. Under oscillating conditions, the Ti64-1100 presented similar or enhanced wear performance with regard to the substrate. The wear resistance of the Ti64-800 coating was lower. This result was attributed to the lower porosity and higher hardness of the Ti64-1100 coating (Table 2) and pointed that the Ti64-1100 coating could be used for repairing aeronautical components subjected to oscillating wear.

\subsection{Wear mechanisms}

A summary table showing the main results about the microstructure and the wear mechanisms that have been identified in the worn samples is presented in Table 4. These results will be described in the next sections. The type of mechanically mixed layer (MML) microstructure has been indicated in this table because it was found to be related to the wear mechanism occurring during the different testing conditions. This relationship was previously reported by Alidokht et al. [15]. From the characterization of the worn samples after the tests, it could be concluded that the major wear mechanisms, in all the samples, were generally abrasion and adhesion, combined with oxidative wear when the samples were tested at $450{ }^{\circ} \mathrm{C}$. However, some peculiarities were found associated to the different types of motion (unidirectional sliding and oscillating) or to the different materials as it is specified below.

Table 4 Summary table reporting the main results that were obtained from each testing conditions. The different MML microstructures were identified as follows: MML1 (mixture of Ti-6Al-4V with counterbody particles which appeared intimately mixed), 
MML2 (layers of Fe or Ti oxides and non-oxidized Ti-6Al-4V material), MML3

(cracked Ti-6Al-4V particles and O contamination), MML4 (trapped debris of oxidized counterbody and Ti-6Al-4V particles).

\begin{tabular}{l|l|l|l|l}
\hline \multicolumn{2}{l}{ Unidirectional Sliding Tests } & Oscillating Tests \\
\hline $\begin{array}{l}\text { General trends } \\
\text { of wear response }\end{array}$ & $\uparrow \mathrm{T}=>\uparrow \mathrm{COF}, \downarrow \delta \mathrm{m}$ & $\begin{array}{l}\text { Substrate and Ti64-1100: } \\
\uparrow \mathrm{T}=>\uparrow \mathrm{COF}, \uparrow \delta \mathrm{m} \\
\mathrm{Ti64-800:} \uparrow \mathrm{T}=>\uparrow \mathrm{COF} ;=\delta \mathrm{m}\end{array}$ \\
\hline $\begin{array}{l}\text { Testing } \\
\text { Temperature }\end{array}$ & RT & $\mathbf{4 5 0}$ & RT & $\mathbf{4 5 0}$ \\
\hline $\begin{array}{l}\text { Wear } \\
\text { mechanisms }\end{array}$ & $\begin{array}{l}\text { Abrasion, } \\
\text { adhesion, } \\
\text { delamination }\end{array}$ & $\begin{array}{l}\text { Abrasion, } \\
\text { adhesion, } \\
\text { oxidation }\end{array}$ & $\begin{array}{l}\text { Abrasion, } \\
\text { adhesion } \\
\text { (besides oxidation } \\
\text { in Ti64-1100) }\end{array}$ & $\begin{array}{l}\text { Abrasion, } \\
\text { adhesion, } \\
\text { oxidation }\end{array}$ \\
\hline Microstructure & MML1 & $\begin{array}{l}\text { MML2; } \\
\text { Ti64-1100: } \\
\text { MML3 }\end{array}$ & $\begin{array}{l}\text { MML1; } \\
\text { Ti64-1100: } \\
\text { MML4 }\end{array}$ & MML3 \\
\hline
\end{tabular}

As it has been pointed above, the COF values were different for each testing condition (Figure 3a). However, the COF values were shown to be similar when comparing the tested materials under the same experimental condition. This observation suggested that the occurring wear mechanisms in each testing condition were similar for all the materials. For this reason, the results are presented here by describing the observed features in the materials at each one of the tested conditions.

\subsubsection{Unidirectional sliding tests at RT}



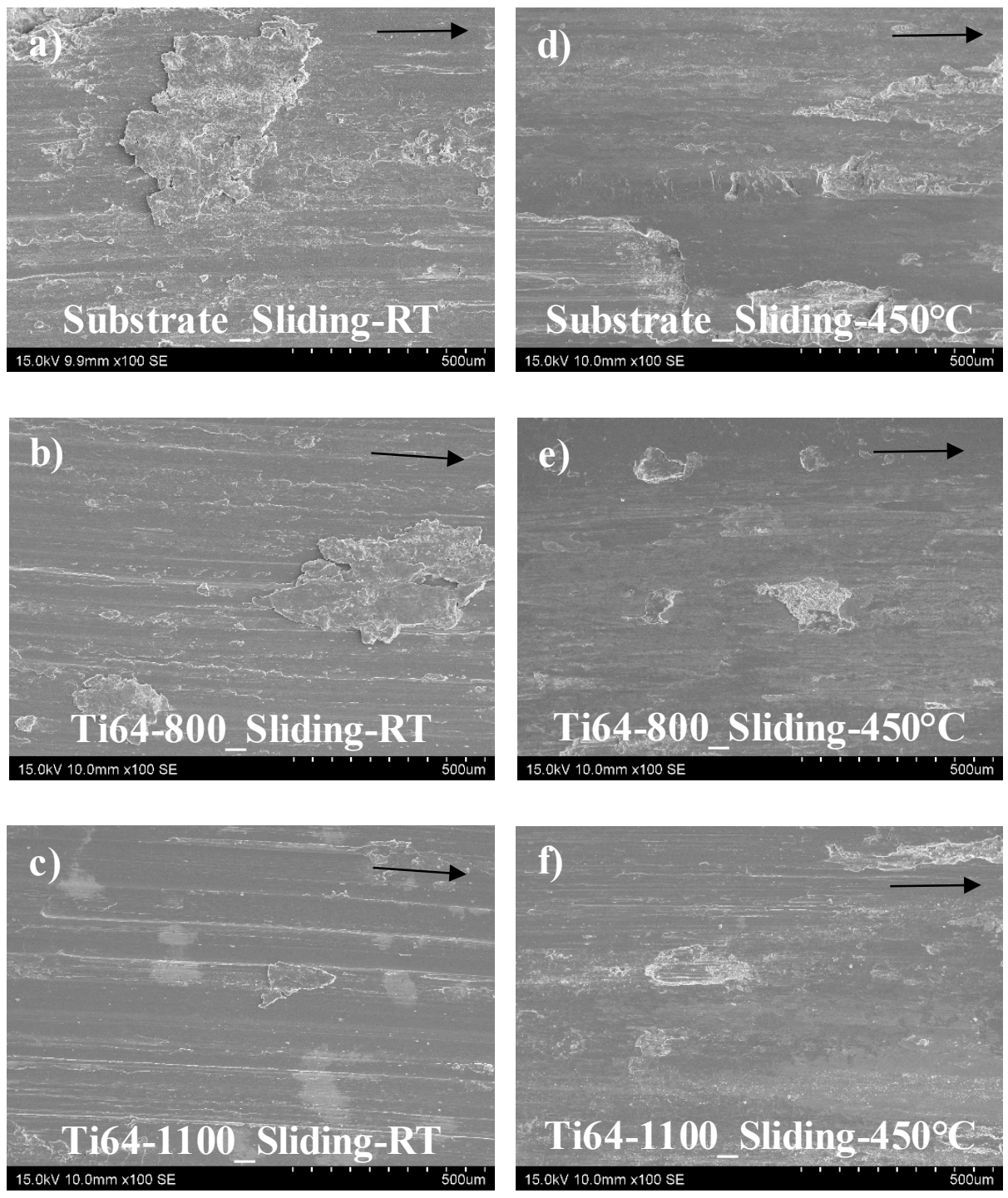

Figure 4 SE micrographs from the worn surface of the substrate (a and d), the Ti64-800 coating (b and e) and the Ti64-1100 coating ( $\mathrm{c}$ and $\mathrm{f}$ ) tested under unidirectional sliding conditions at $\mathrm{RT}$ and at $450{ }^{\circ} \mathrm{C}$.

The involved wear mechanisms during the unidirectional sliding tests at RT were shown to be abrasion and adhesion. The worn surface of the samples tested under unidirectional sliding conditions at RT presented abrasive grooves as it is shown in Figure $4 \mathrm{a}, \mathrm{b}$ and $\mathrm{c}$. Adhesive signs between the pin and the counterbody were also deduced by the observation of areas where material appeared to have been detached. Figure $5 \mathrm{a}$ and $\mathrm{b}$ show higher magnification images from Figure $4 \mathrm{a}$ and $\mathrm{b}$ which belong 
to the substrate and the Ti64-800 coating, respectively, where adhesive signs are indicaed by arrows. The formation of tribo-layers due to adhesion was observed as shown in Figure 5b. In addition, counterbody material was transferred to the pin during the tests. An example of this is shown in Figure $5 \mathrm{~b}$ which is a BSE image acquired from a worn Ti64-800 sample, where the brigtest spots corresponded to Fe rich particles as revealed by EDX (Figure 5c). Large particle agglomerates were also observed on the surfaces measuring hundreds of microns in size as well as micron sized particles which appeared dispersed over the surfaces (Figure 4a, b and c). The particle agglomerates were formed by a mixture of Ti-6Al-4V and counterbody material as indicated by EDX microanalysis.

An MML was observed at the near surface of the studied cross-sectional cuts of the samples. Figure $6 \mathrm{a}, \mathrm{b}$ and $\mathrm{c}$ present images from cross sectional cuts of the worn samples at RT, in which roughly continuous MMLs were observed. The thicknesses of the MMLs were not equal along the entire cross section. Maximum MML thicknesses of $\sim 81 \mu \mathrm{m}, \sim 36 \mu \mathrm{m}$ and $\sim 10 \mu \mathrm{m}$ were measured in the substrate, the Ti64-800 and the Ti64-1100 coatings respectively. The composition of the MMLs consisted of a mixture of Ti-6Al-4V alloy with traces of counterbody material as revealed by EDX microanalysis. An example of these microanalysis is shown in Figure 6d which corresponds to the pointed sites in the Ti64-1100 micrograph in Figure 6c. The counterbody particles were distinguished as the brightest phases in the BSE images (Figure $6 \mathrm{a}, \mathrm{b}$ and $\mathrm{c}$ ). The particles composing the MML presented elongated shapes indicating that they have been plastically deformed. Moreover, both coatings, sprayed at $800{ }^{\circ} \mathrm{C}$ and $1100{ }^{\circ} \mathrm{C}$, appeared to fail under these testing conditions because delamination wear was important in these samples, as it is shown in Figure 6e and $\mathrm{f}$ for 
the Ti64-1100 coating. These observations were in accordance with the obtained higher wear rates for these samples (Figure 3b).

The generated MML structure suggested that it could have been formed through a process which has been referred in literature as the formation of a mechanically mixed layer, or transfer layer $[23,24]$. This model consists on the initial detachment of a fragment of material, by adhesion from one surface to the surface of the counterpart, and the following detachment of more fragments, which become adhered to the previously formed. If the particle aggregates, which are typically named as transfer particles, remain trapped in the contact, they are subsequently subjected to plastic deformation. This deformation has been compared to the mechanical mixing which occurs in a ball milling mechanical alloying [24]. The trapped particles at the contact may also exert an abrasive action on the sample surface generating abrasive grooves. Moreover, the presence of Fe rich particles in the MML and debris was not expected due to the higher hardness of the counterbody material. However this result could be as a consequence of a thermal softening effect due to the temperature increments at the asperity contacts. In addition, the presence of Fe on the MML has also been reported by other researchers when testing Ti against steel $[12,25]$.
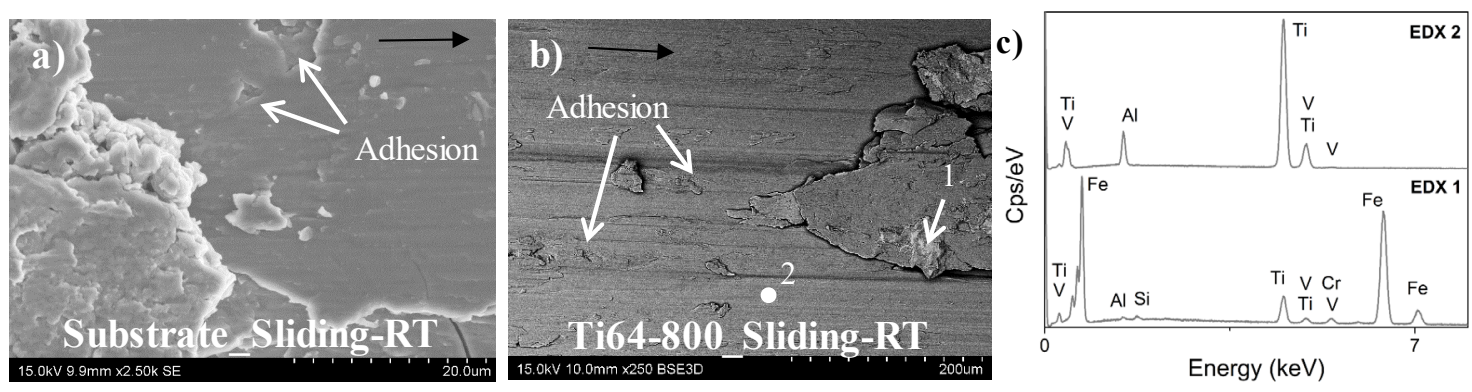

Figure 5 a) SE image from the worn surfaces of the substrate tested under unidirectional sliding at RT showing adhesion signs. b) BSE image from the worn surfaces of the Ti64-800 
coating tested under unidirectional sliding at RT and c) EDX microanalysis acquired from the sites indicated in (b).
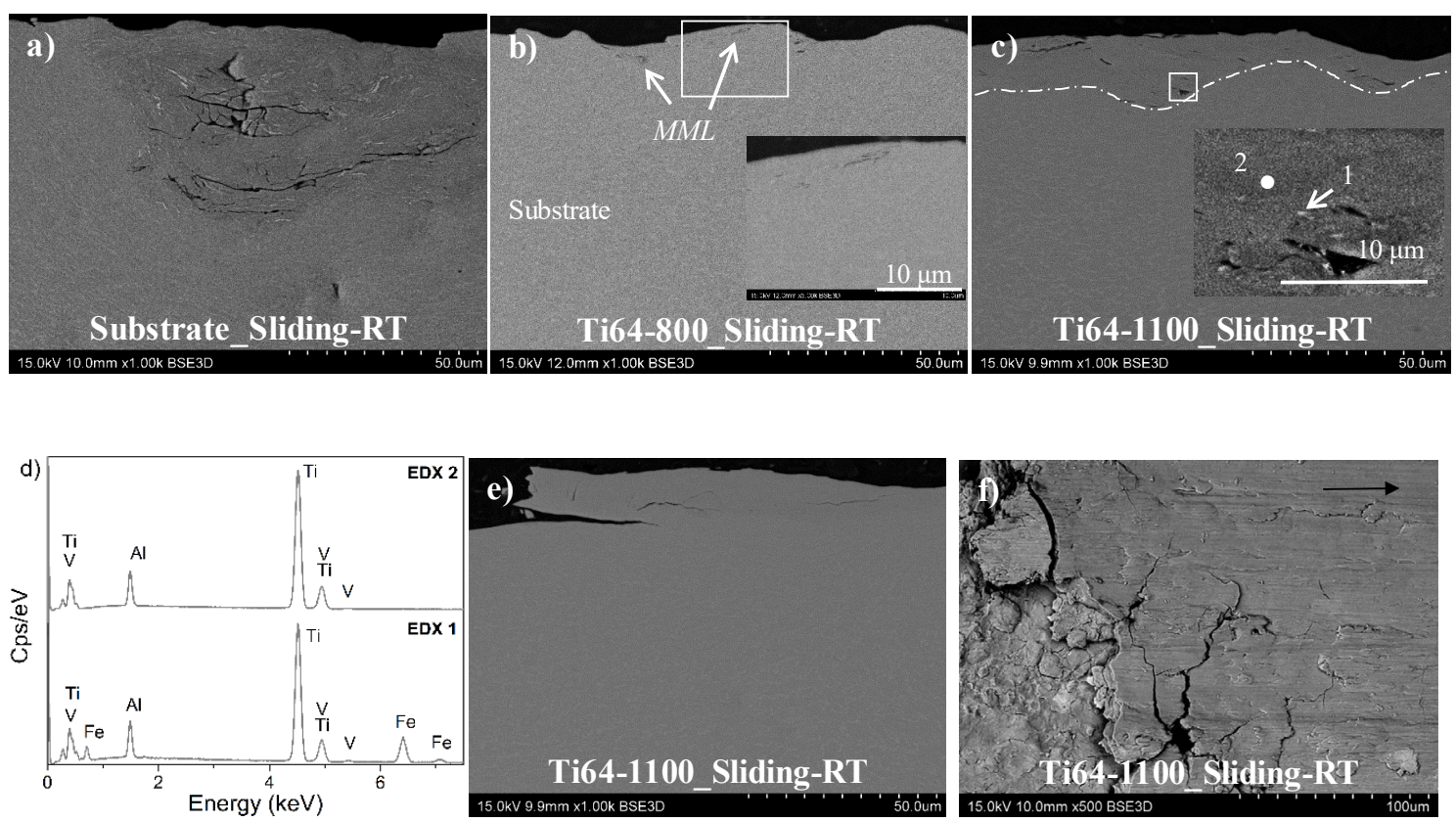

Figure 6 BSE images showing the cross sections of the worn samples after sliding tests conducted at RT of a) the substrate, b) the Ti64-800 and the c) Ti64-1100 coatings, in which the dotted line indicates the MML thickness. d) EDX microanalysis from the sites indicated in (c) of the MML generated in the Ti64-1100 coating and e,f) BSE images from the cross-section and the surface, respectively, of the same sample where delamination was observed.

\subsubsection{Unidirectional sliding tests at $450{ }^{\circ} \mathrm{C}$}

The samples tested with unidirectional sliding movement at $450{ }^{\circ} \mathrm{C}$ were shown to be subjected to abrasive, adhesive and oxidative wear. As it can be seen in Figure 4d, e and $\mathrm{f}$, the surfaces of the samples, after the unidirectional sliding tests performed at $450{ }^{\circ} \mathrm{C}$, seemed to be qualitatively smoother as compared to the worn surfaces of the same materials performed at RT (Figure 4a, b and c). The large debris particles which were observed on the samples tested at RT were not observed on these samples, suggesting 
that abrasion may have occurred by the action of smaller particles, and thus it led to the formation of smoother worn surfaces. On the other hand, the surfaces appeared broken at some sites pointing that adhesive wear occurred. Figure $7 \mathrm{a}$ and $\mathrm{b}$ show details of these adhesive signs on the surfaces of Ti64-1100 and Ti64-800 worn samples. The higher temperature environment appeared to have led to localised welds between the two counterparts. In addition, oxide phases were shown to be generated during the tests as revealed by EDX microanalysis. This result is shown in Figure $7 \mathrm{~b}$ and $\mathrm{c}$ which correspond to the worn surface of a Ti64-800 sample. The chemical composition of the oxides was based on mixtures of $\mathrm{Ti}, \mathrm{Al}, \mathrm{V}$ and Fe elements. It has not been possible to determine the type of oxides generated through these analyses.

It should be noted that the microstructure of the MML of the Ti64-1100 coating, which was observed after the unidirectional sliding tests at $450{ }^{\circ} \mathrm{C}$, was different from the one formed in the other tested materials. The MMLs formed on the substrate and Ti64-800 samples consisted of layers of oxidized Ti-6Al-4V and counterbody material and nonoxidized Ti-6Al-4V. Micrographs of the MMLs of the substrate and the Ti64-800 coating samples are shown in Figure 8a and b, with the EDX map microanalysis of a detail from the MML of the worn Ti64-800 coating sample (Figure 8c). The oxide layers consisted mainly of Fe oxides, and it was apparent that Ti oxides were also formed. The thickness of the MML was about $\sim 54 \mu \mathrm{m}$ in the substrate and $\sim 66 \mu \mathrm{m}$ in the Ti64-800 coating. On the other hand, the MML in the worn Ti64-1100 coating sample exhibited cracked Ti-6Al-4V particles with oxygen contamination (Figure 9). A maximum MML of $\sim 8 \mu \mathrm{m}$ was measured in this sample. In addition, the COF of the Ti64-1100 coating was shown to be slightly higher and the wear rate was lower as compared to that of the others (Figure $3 \mathrm{a}$ and $\mathrm{b}$ ). The different wear behaviour of this 
coating could be as a consequence of the higher hardness of this coating and its different microstructure (Table 2).

The higher contribution of adhesive wear at $450{ }^{\circ} \mathrm{C}$ explains the higher $\mathrm{COF}$ measured at high temperatures (Figure 3a). On the other hand, it has been found that the wear rates of the unidirectional sliding tests were diminished when increasing the testing temperature (Figure 3b). Therefore, the oxides that have been generated on the surfaces of the samples were shown to provide a higher wear resistance. This could be due to the higher hardness values of the oxides as compared to the non-oxidized Ti.
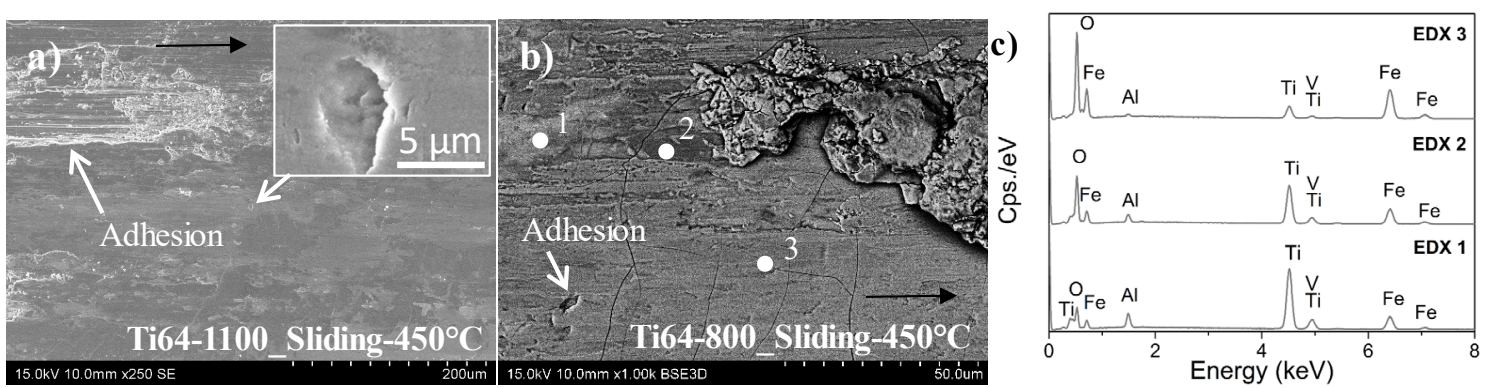

Figure 7 a) SE image showing adhesive signs on the surface of a Ti64-1100 worn sample after unidirectional sliding test at $450{ }^{\circ} \mathrm{C}, \mathrm{b}$ ) BSE micrographs showing a plan view area of a worn sample of the Ti64-800 coating after a unidirectional sliding test conducted at $450{ }^{\circ} \mathrm{C}$ and c) the EDX microanalyses acquired from the sites indicated in (b).
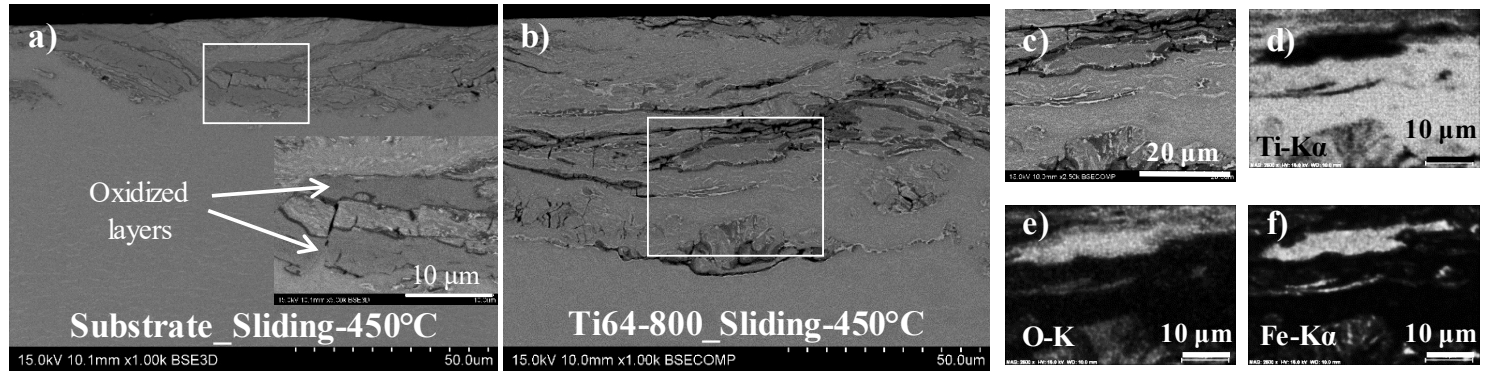

Figure 8 BSE image showing the cross sections of the worn samples of a) the substrate and b) the Ti64-800 coating after unidirectional sliding tests conducted at $450{ }^{\circ} \mathrm{C}$, c) a 
detail of the MML of the Ti64-800 sample in (b) and d) Ti-Ka, e) O-K and f) Fe-Ka EDX maps from this area.
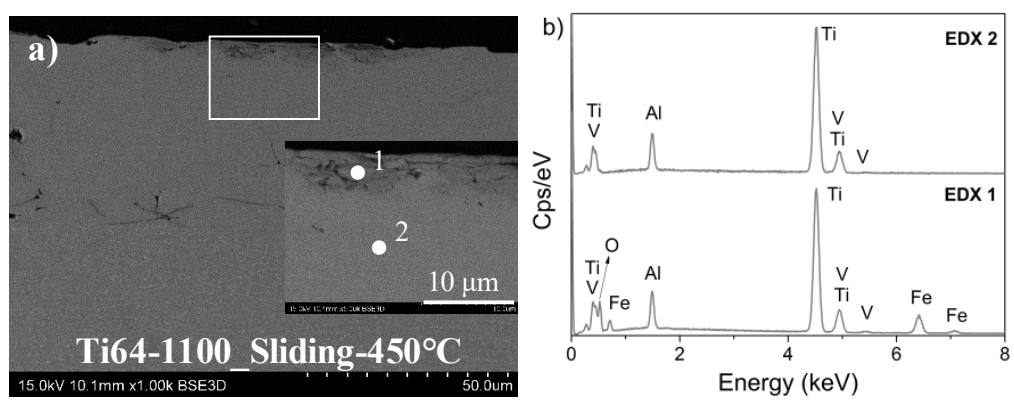

Figure 9 a) BSE image showing the cross section of a worn sample of the Ti64-1100 coating after an unidirectional sliding test conducted at $450{ }^{\circ} \mathrm{C}$, and b) EDX microanalysis from the sites indicated in (a).

\subsubsection{Oscillating tests at RT}



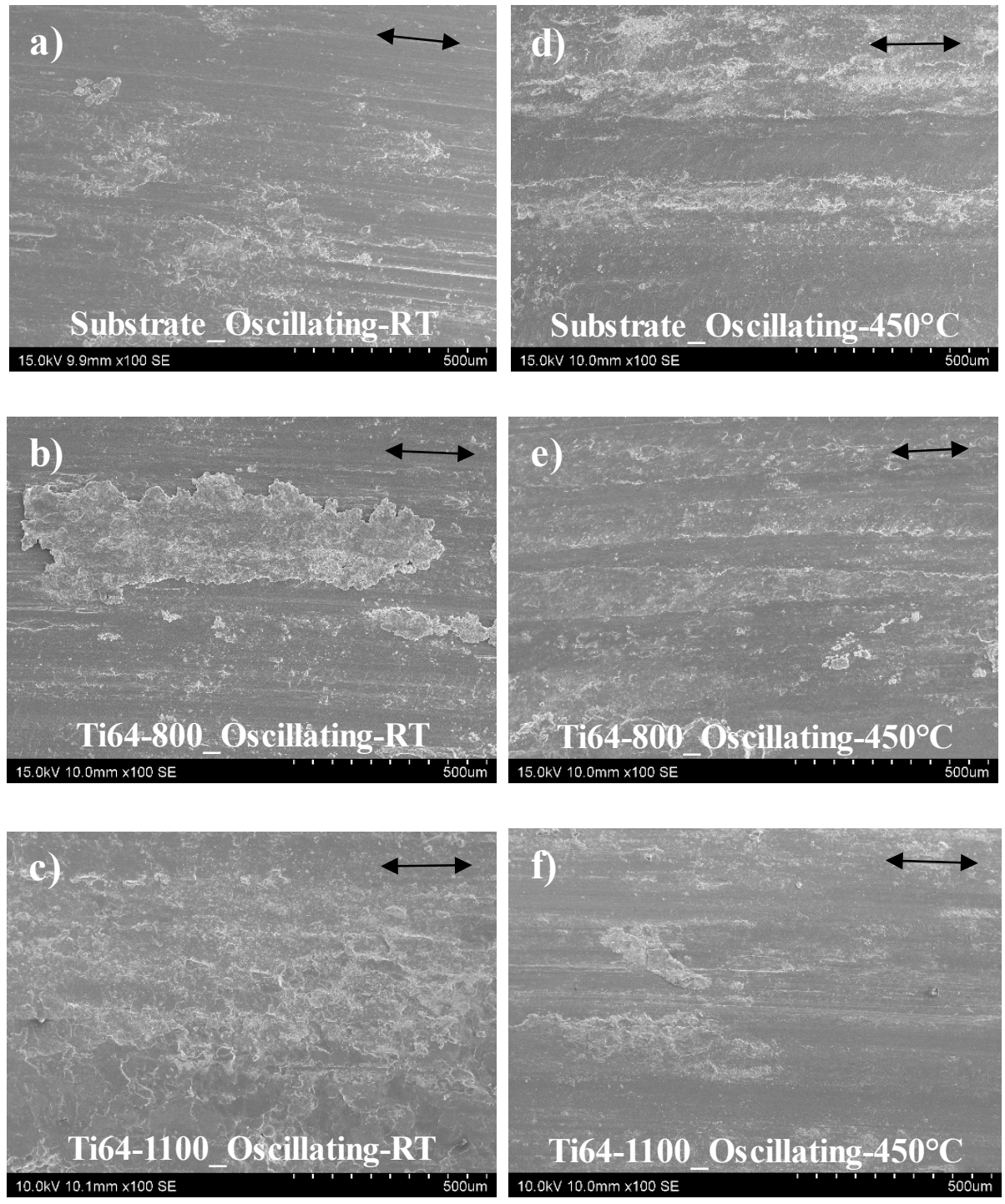

Figure 10 SE micrographs from the worn surface of the substrate (a and d), the Ti64800 coating (b and e) and the Ti64-1100 coating ( $\mathrm{c}$ and $\mathrm{f}$ ) tested under oscillating conditions at RT and at $450{ }^{\circ} \mathrm{C}$.

Regarding to the oscillating tests at RT, the main wear mechanisms were abrasion and adhesion. Figure 10a, b and c show micrographs of the plan view surfaces of the substrate, the Ti64-800 coating and the Ti64-1100 coating worn samples tested under oscillating conditions at RT. Scratches were generated by abrasion, as it can be observed in the micrographs. In addition, debris was observed on the surfaces as loose or assembled particles. Figure 11a and b shows an example of this in a worn Ti64-800 
sample surface. As can be seen in the EDX 2 microanalysis, some oxygen was also present at the debris particles but in a small quantity. EDX microanalysis revealed that counterbody debris material was also found adhered to the surfaces. This result indicated that $\mathrm{Ti}$ or Fe oxides (or some compound based on both elements) might have been created during the wear test, or that oxygen has been incorporated as an impurity [26]. The presence of a larger amount of debris products in the Ti64-800 sample surface suggested a poorer wear resistance of this coating under these testing conditions. This fact could be correlated to the higher wear rate of this coating as it has been shown in the bar graphs in Figure $3 b$.
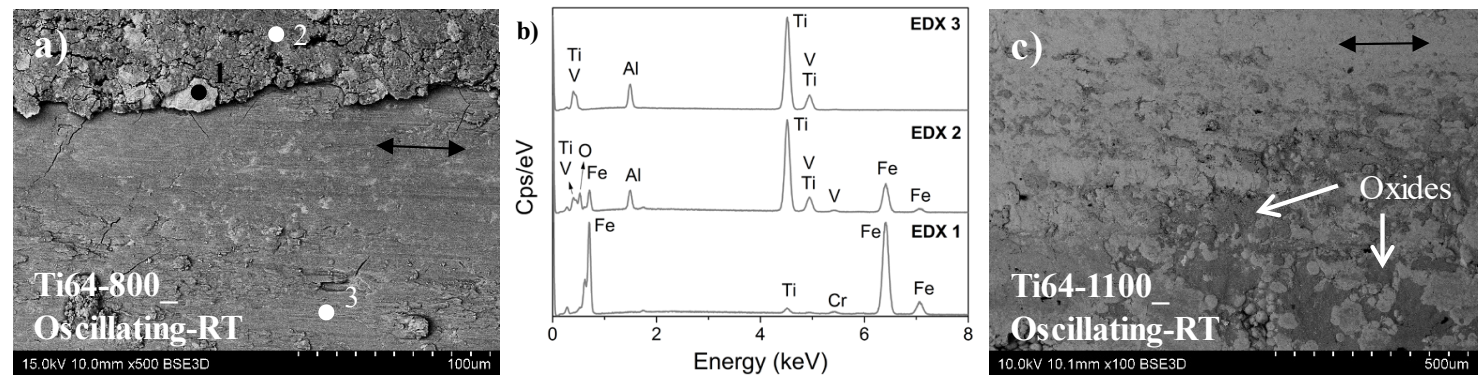

Figure 11 a) BSE images from the worn surface of a Ti64-800 coating tested under oscillating conditions at RT. b) EDX microanalysis from the sites indicated in (a). c) BSE image from the worn surfaces of the Ti64-1100 coatings tested under oscillating conditions at RT.

In the case of the Ti64-1100 coating, oxidative wear was also found during the oscillating tests at RT by the presence of oxide particles on its surface (Fe and $\mathrm{Ti}$ oxides) (Figure 11c). This feature could explain the lower COF and wear rate obtained for this coating (Figure 3 ). The oxide particles could have been performing a rolling effect between the pin and the disc and thus, decreasing the COF. In addition, it is worth pointing out that the Ti64-1100 coating tested under oscillating movement at RT exhibited the lower wear rate compared to the other materials. 
An MML was distinguished after the test on the studied cross-sectional cuts as it is shown in Figure 12 and Figure 13. The MMLs were roughly continuously distributed along the cross section and they presented a maximum thickness of $\sim 27, \sim 10$ and $\sim 20$ $\mu \mathrm{m}$ in the substrate, Ti64-800 and Ti64-1100 coatings respectively. The composition of the layer was based on a mixture of Ti-6Al-4V and counterbody particles in the substrate and in the Ti64-800 samples. The EDX of a transferred particle in the MML of the substrate is shown in Figure 12b. This microstructure was similar to that developed during the sliding tests at RT and the same MML formation model of mechanical mixing could be adequate to explain its development.
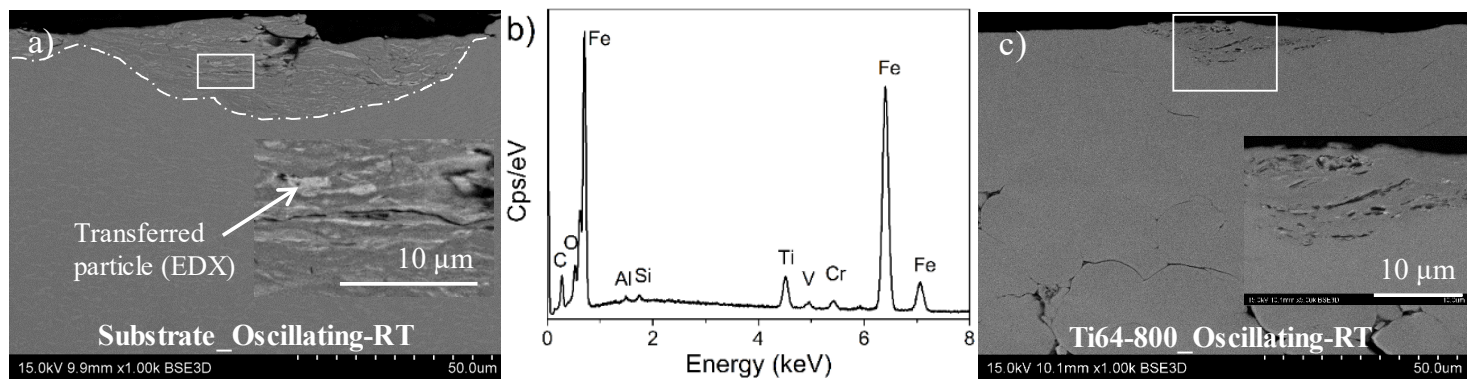

Figure 12 a) BSE image showing the cross section of a worn sample of the substrate after an oscillating test conducted at RT (the dotted line indicates the extension of the MML) and b) the EDX microanalysis acquired from a transferred particle from the counterbody which is pointed in (a). c) BSE image showing the cross section of a worn sample of the Ti64-800 coating after an oscillating test conducted at RT.
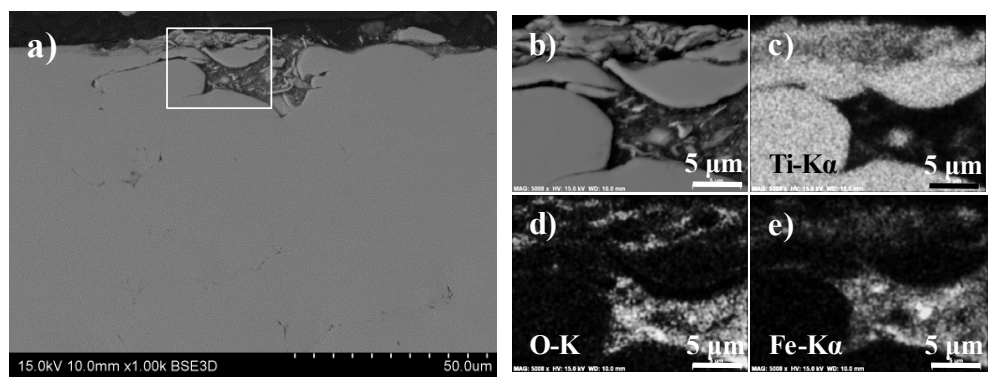
Figure 13 a) BSE image showing the cross section of a worn sample of the Ti64-1100 coating after an oscillating test conducted at RT. b) Detail of the MML and the c) Ti$\mathrm{K} \alpha$, d) O-K and e) Fe-K $\alpha$ EDX maps from the MML.

On the other hand, the microstructure of the MML in the Ti64-1100 sample presented Fe oxides which were mixed with Ti-6Al-4V particles. A micrograph of this MML and an EDX map analysis of a detail of it are shown in Figure 13. The Ti-6Al-4V particles did not appear to have been oxidized. The study of the cross section revealed that the formation of Ti oxides was not clear because the oxygen content was more appreciable at the same sites where Fe was detected. TEM technique was therefore used in order to find out whether oxidation affected only to the counterbody or to both counterparts. TEM micrographs showed that nanosized grains regions were formed at the most superficial zone of the surface which were extended into the coating up to several microns (Figure 14). This feature can be observed in the magnified regions of the sites named as SADP1 and SADP2 in Figure 14. The ring SADPs obtained from these regions also indicated the formation of nanocrystalline areas. On the other hand, the presence of larger grains was also observed at the near surface region as the one referred as SADP3 in the figure. These grains presented sizes in the order of a few microns and appeared to be deformed. A mixture of amorphous oxides with $\alpha$-Fe rich phases from the counterbody (SADPs 4, 5 and 6) and $\alpha$-Ti rich phases from the coating (SADP6) were found as revealed by electron diffraction (Figure 14) and STEM analyses (Figure 15). The amorphous oxides appeared to be Fe oxides as inferred from the EDX-STEM maps. STEM analyses also indicated that particles from the counterbody were mixed as traces within the upper nanocrystalline $\alpha$-Ti rich area. Therefore, the TEM study confirmed that the MML generated during the test was constituted by amorphous Fe oxides and some Ti-6Al-4V and Fe rich particles, as it has been observed by SEM. 
Moreover, the coating was shown to have been subjected to a severe plastic deformation at the most superficial surface as indicated by the nanosized grain microstructure. The origin of the $\mathrm{Fe}$ oxides could have been either due to an oxidation reaction during the test or it could have come from the naturally formed passive layer on the steel surface.

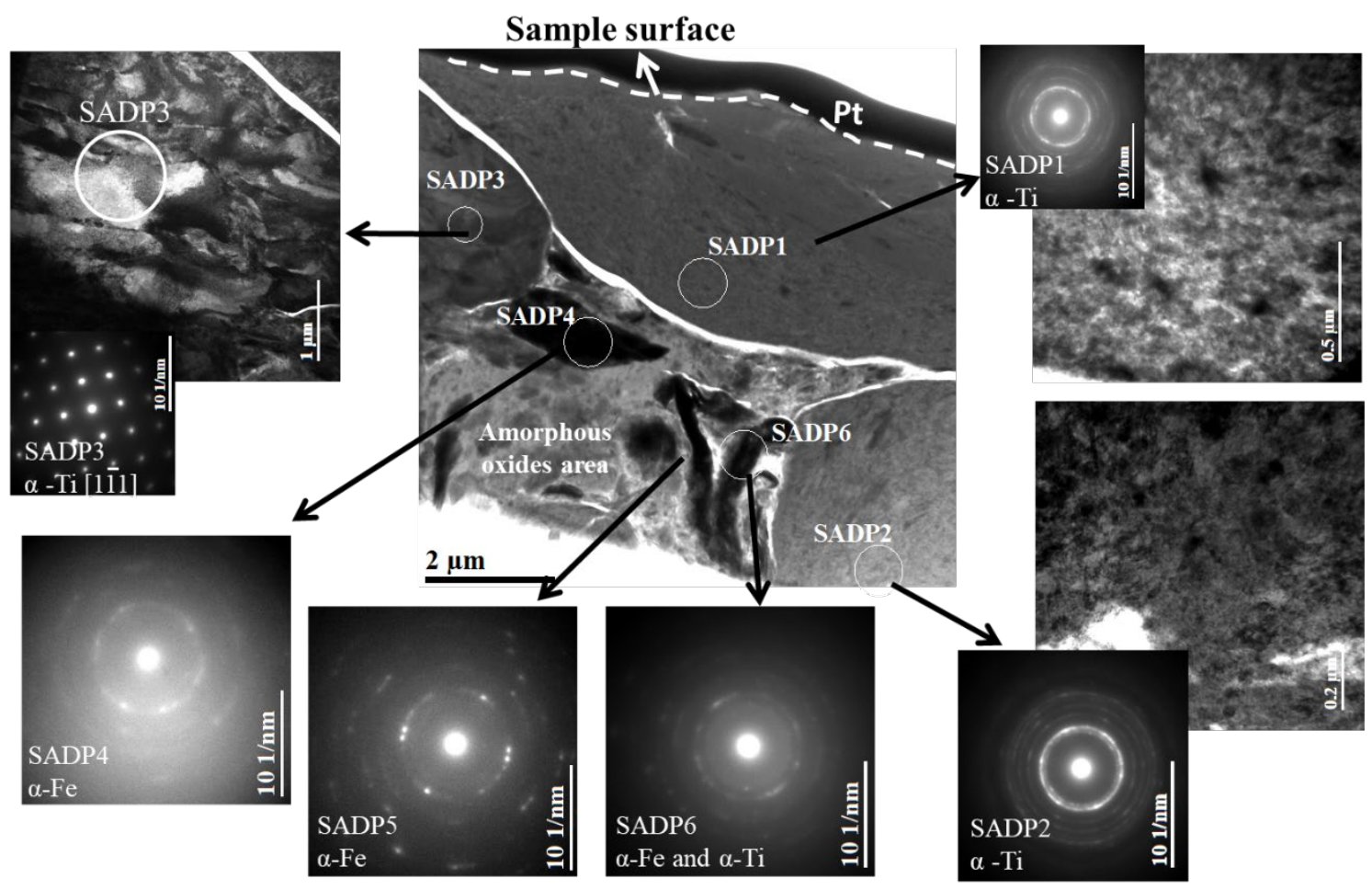

Figure 14 BF images of a cross sectional cut of a Ti64-1100 sample tested at RT.

Higher magnification images from different regions in the sample are included in the figure as well as SADPs acquired from the regions indicated by arrows.
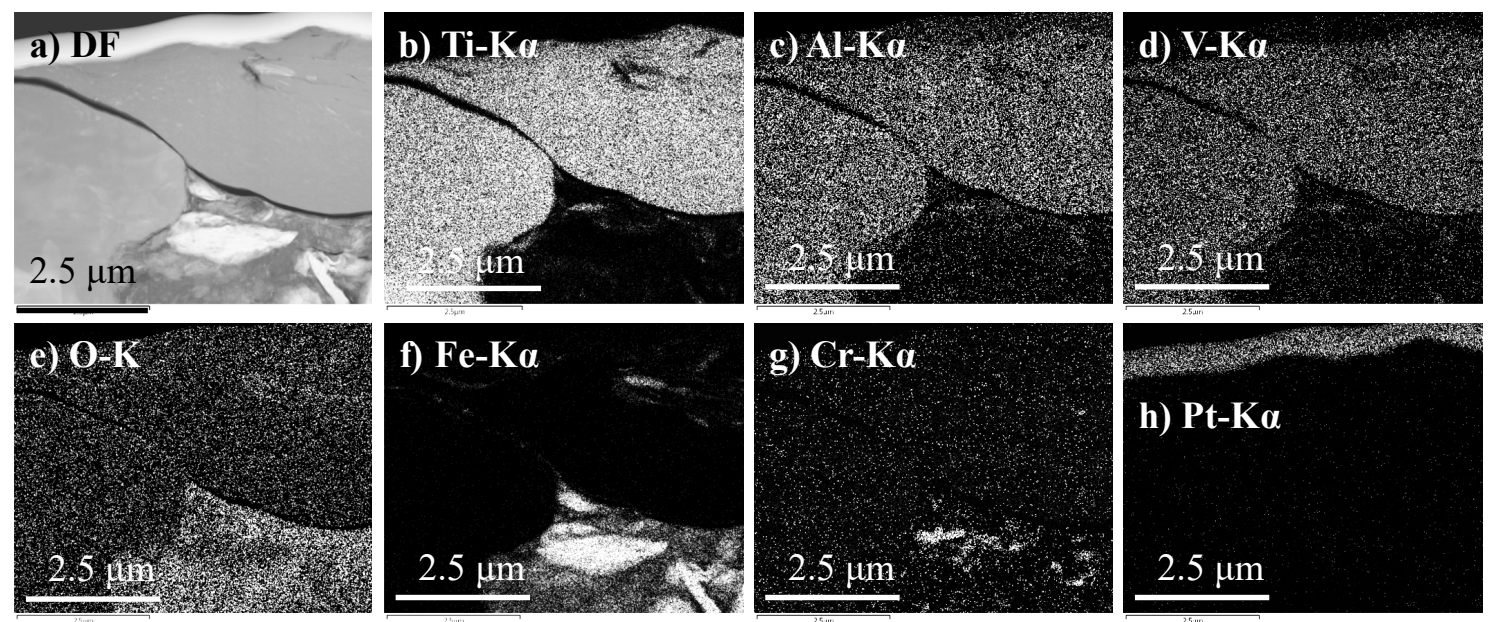
Figure 15 a) DF and the EXD-STEM maps of b) Ti-Ka, c) Al-Ka, d) V-Ka, e) O-K, f) $\mathrm{Fe}-\mathrm{K} \alpha, \mathrm{g}) \mathrm{Cr}-\mathrm{K} \alpha$ and $\mathrm{h}$ ) Pt-K $\alpha$ acquired from the same area which corresponds to the Ti64-1100 worn sample presented in Figure 14.

The results obtained from the TEM study of the Ti64-1100 samples, tested at RT, further support the idea of the mechanical mixing of transferred particles from both counterpairs. In this sample, nanosized grain regions were found at the near surface which were composed by mixtures of Ti-6Al-4V and Fe rich phases. Although no phases were found being composed as an alloy of elements from each counterpair, the particles appeared intimately mixed. Therefore, as the chemical composition and mechanical properties of this layer differed from that of the unworn material, the wear response was mainly dependent on the properties of this layer. It could be concluded that, in the samples tested at RT, the near surface of the sample was mainly modified by the action of adhesive wear as well as material transference from the counterbody and plastic deformation. Oxidative wear has also been identified in the Ti64-1100 sample, although in a minor contribution, which led to the formation of oxidized wear particles of counterbody material that some of them were incorporated to the transfer particles.

On the other hand, the formation of a different MML in the Ti64-1100 coating but not in the substrate could be explained because of the higher hardness, their different microstructure and the higher roughness of the Ti64-1100 coating surface. The MML appeared to be a consequence of debris entrapment within the asperities of the coating which had not been worn because they were hard enough to bear the shearing stresses during the test.

\subsubsection{Oscillating tests at $450{ }^{\circ} \mathrm{C}$}


The wear mechanisms that were detected in the oscillating tests at $450{ }^{\circ} \mathrm{C}$ were abrasion, adhesion and oxidation. The appearance of the worn surfaces after the oscillating tests performed at $450{ }^{\circ} \mathrm{C}$ are shown in Figure $10 \mathrm{~d}$, e and $\mathrm{f}$. The surfaces morphologies seemed to be qualitatively smoother than those generated after the oscillating tests at RT. The smoother surfaces could be explained because of the smaller size of the debris particles that were found on the surfaces as compared with the larger particle agglomerates that were observed on the pins' surfaces after the RT tests. However, it should be noted that larger debris particle might have been present at the contact during the tests and they could have been removed from the pin surface during the cleaning before microscopy analysis. In addition, a larger amount of oxidized debris were observed covering the samples surfaces and some areas of the surfaces were oxidized. This result is shown in Figure 16, which presents a BSE image from the surface of a worn Ti64-1100 sample and the EDX microanalysis from different sites on the surface.
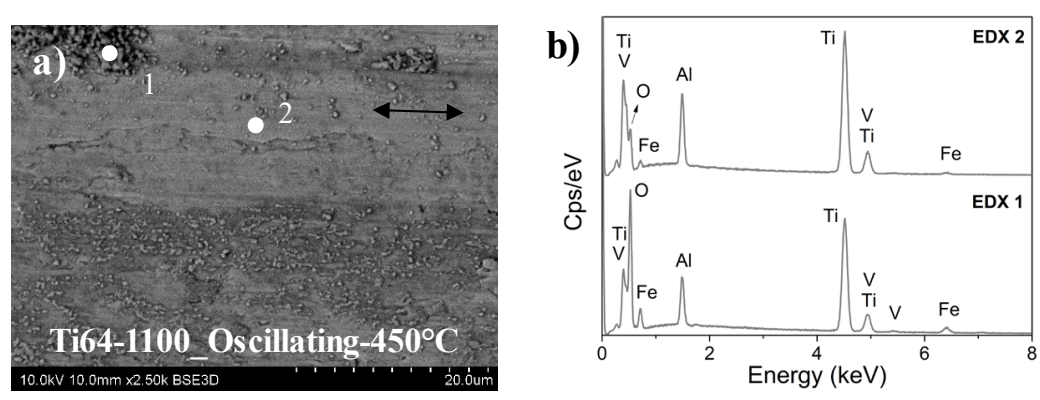

Figure 16 a) BSE micrographs showing a plan view area of a worn sample of the Ti641100 coating after an oscillating test conducted at $450{ }^{\circ} \mathrm{C}$, and b) the EDX microanalysis acquired from the sites indicated in (a).

The MML microstructures were shown to differ from that generated during the unidirectional sliding tests at $450{ }^{\circ} \mathrm{C}$. Figure 17 and Figure 18 show micrographs of the MMLs generated in the substrate the Ti64-800 and Ti64-1100 worn samples. In this 
case, an MML formed by cracked Ti-6Al-4V particles was generated in all the samples. This microstructure was similar to that observed after the sliding tests at $450{ }^{\circ} \mathrm{C}$ in the Ti64-1100 coating. The cracks were shown to penetrate up to a maximum depth of $\sim 12$ $\mu \mathrm{m}$ in the substrate and the Ti64-800 coating and up to $\sim 8 \mu \mathrm{m}$ in the Ti64-1100 coating. The EDX microanalysis indicated the presence of $\mathrm{Ti}, \mathrm{Fe}$ and $\mathrm{O}$ at the oxidized phases, but it was not possible to determine the particular type of oxide that has been formed from this information. An example of the EDX analysis is shown in Figure 18 for the Ti64-1100 coating. The cracked appearance and the presence of oxygen suggested a major role of oxidative wear in these samples. The formation of cracks at the near surface could be attributed to the inward diffusion of oxygen and to the formation of oxides at the near surface of the samples. Ti alloys have been reported to be hardened when oxygen is present in solid-solution and this effect results detrimental for ductility and fatigue strength [26]. For this reason, it is likely that the near surface of the Ti-6Al$4 \mathrm{~V}$ alloy was more brittle and could have caused the cracking of the material.
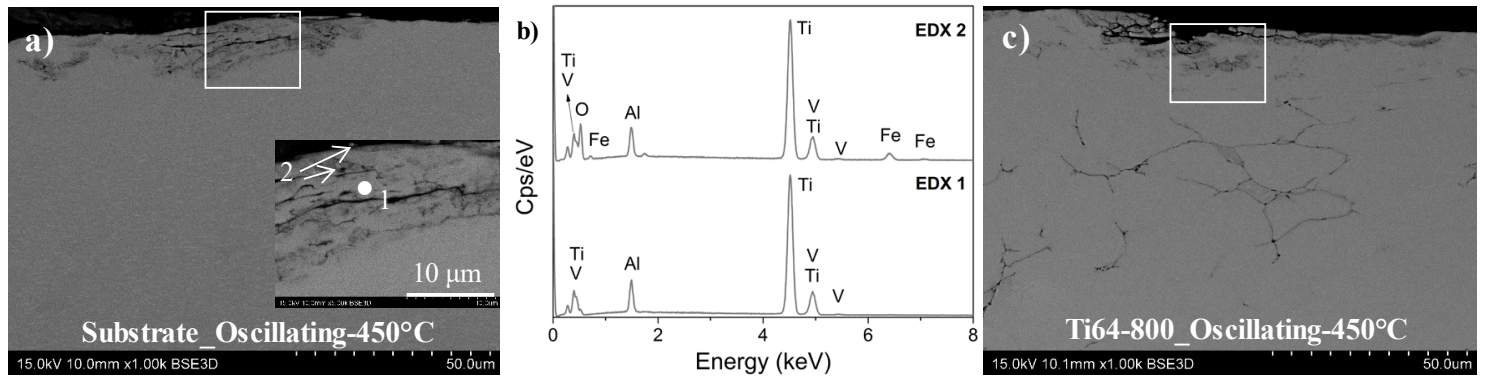

Figure 17 a) BSE image showing the cross section of a worn sample of the substrate after an oscillating test conducted at $450{ }^{\circ} \mathrm{C}$ and b) the EDX microanalysis acquired from the sites indicated in (a). c) BSE image showing the cross section of a worn sample of the Ti64-800 coating after an oscillating test conducted at $450{ }^{\circ} \mathrm{C}$. 

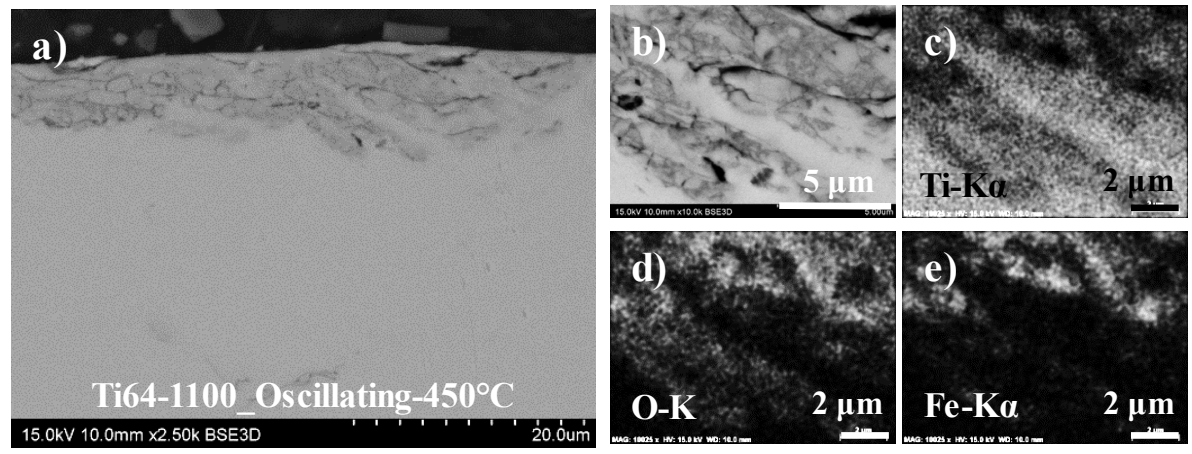

Figure 18 a) BSE image showing the cross section of a worn sample of the Ti64-1100 coating after an oscillating test conducted at $450^{\circ} \mathrm{C}$. b) Detail of the MML and the c) Ti-K $\alpha$, d) O-K and e) Fe-Ka EDX maps from the MML.

The near surface of a worn Ti64-1100 sample was investigated by TEM in order to identify the oxide phases and the fine microstructure. Figure 19 presents a TEM micrograph of a cross-sectional cut prepared by FIB. A layer with an approximate thickness of $\sim 1 \mu \mathrm{m}$ was observed at the most superficial region of the sample which was constituted by $\mathrm{Ti}$ and $\mathrm{Fe}$ oxides generating a nanocrystalline grain microstructure (Figure 19 and Figure 20). The presence of $\mathrm{TiO}_{2}$ and $\mathrm{Fe}_{3} \mathrm{O}_{4}$ oxides was identified by electron diffraction analyses as can be seen in the SADPs named as DP2 and DP3 in Figure 19. Pores were also observed between the particles as can be seen in Figure 19 and Figure 20b. Below these oxides layer, the grains of the coating presented equiaxed morphologies as can be seen in the magnified bright field image from the region referred as R2 in Figure 19. These grains presented the $\alpha$-Ti structural phase and their elemental composition was that of the Ti-6Al-4V. A diffraction pattern of one of these grains is reported in Figure 19.

It should be noted that the oxidation of the pin has also been detected in this type of microstructure, suggesting that the oxidation of the pin was only significant when the tests were performed at the highest temperatures. In contrast, it has been previously 
shown that the oxidation of the steel was more favoured than that of the pin at lower temperatures. A possible explanation for these findings could be the higher oxidation resistance of the Ti alloy with regard to the $100 \mathrm{Cr} 6$ steel. The TEM investigation also revealed that the grains within the particles located at the near surface presented nanometric sizes probably due to the higher plastic deformation or chemical transformations at the top surface. However, the presence of these particles with nanosized grains was found until shallower depths when compared to that observed in the samples tested at lower temperatures. Therefore, one of the major wear mechanisms occurring in the samples tested at $450{ }^{\circ} \mathrm{C}$ has been shown to be oxidative. Other mechanisms, as adhesion and abrasion, were also found. These results support the inferred idea from the SEM investigation. However, these findings contrast with that observed by Hager et al. [27] in a study about the effect of high temperature on the fretting wear regime at Ti-6Al-4V interface. They show in this study that a high temperature environment promotes oxidation and thermal softening. However, the observed embrittlement of the near surface of the samples in the present investigation could be explained because of the heating time of the attached furnace to the test rig before starting the test. The test was started when the system temperature achieved 450 ${ }^{\circ} \mathrm{C}$ and thus, oxygen diffusion might have occurred during the heating stage. 

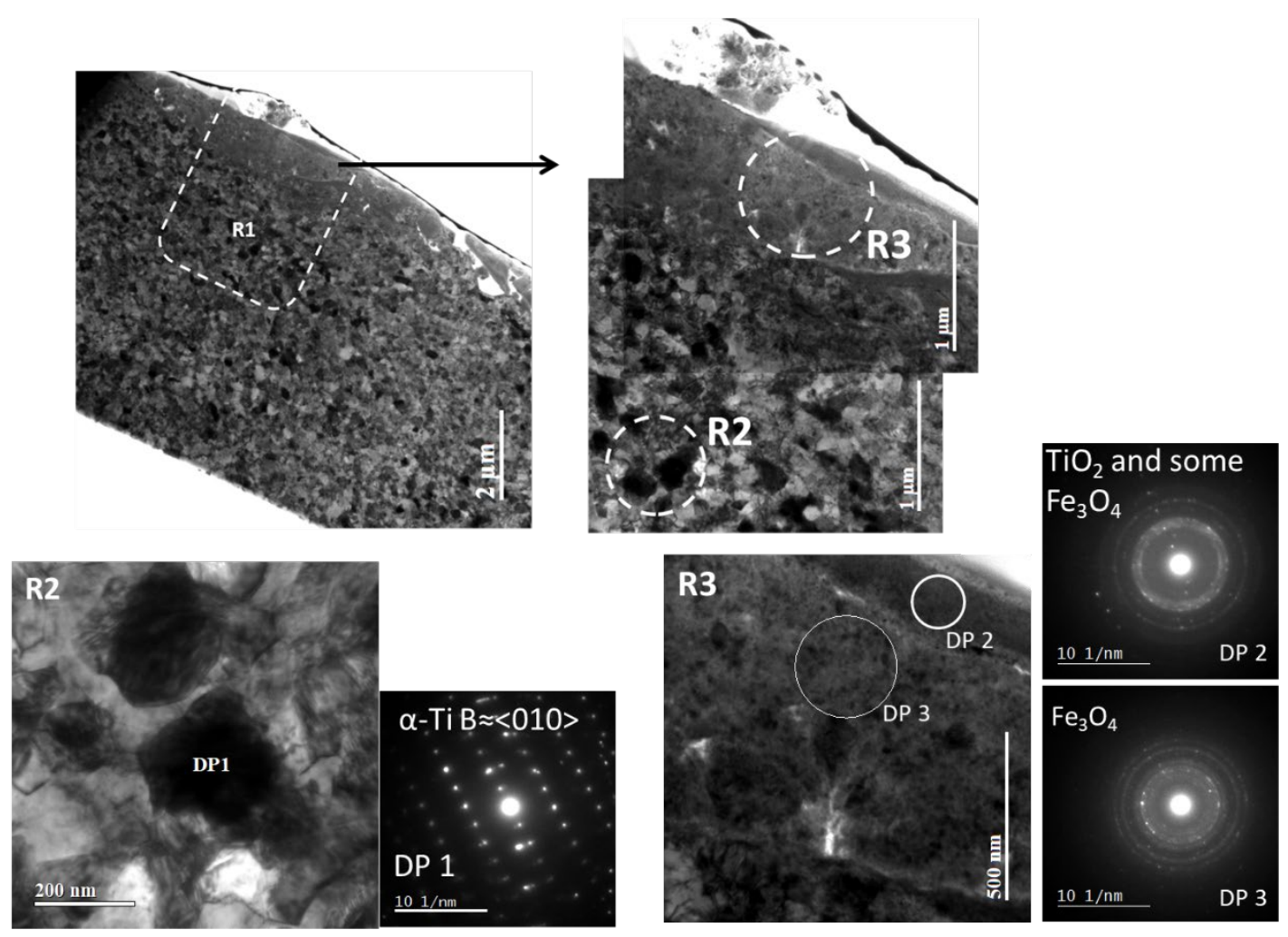

Figure 19 BF images of a cross sectional cut of a Ti64-1100 sample tested at $450{ }^{\circ} \mathrm{C}$.

Higher magnification images from different regions in the sample are included in the figure as well as SADPs acquired from the areas indicated as DP.
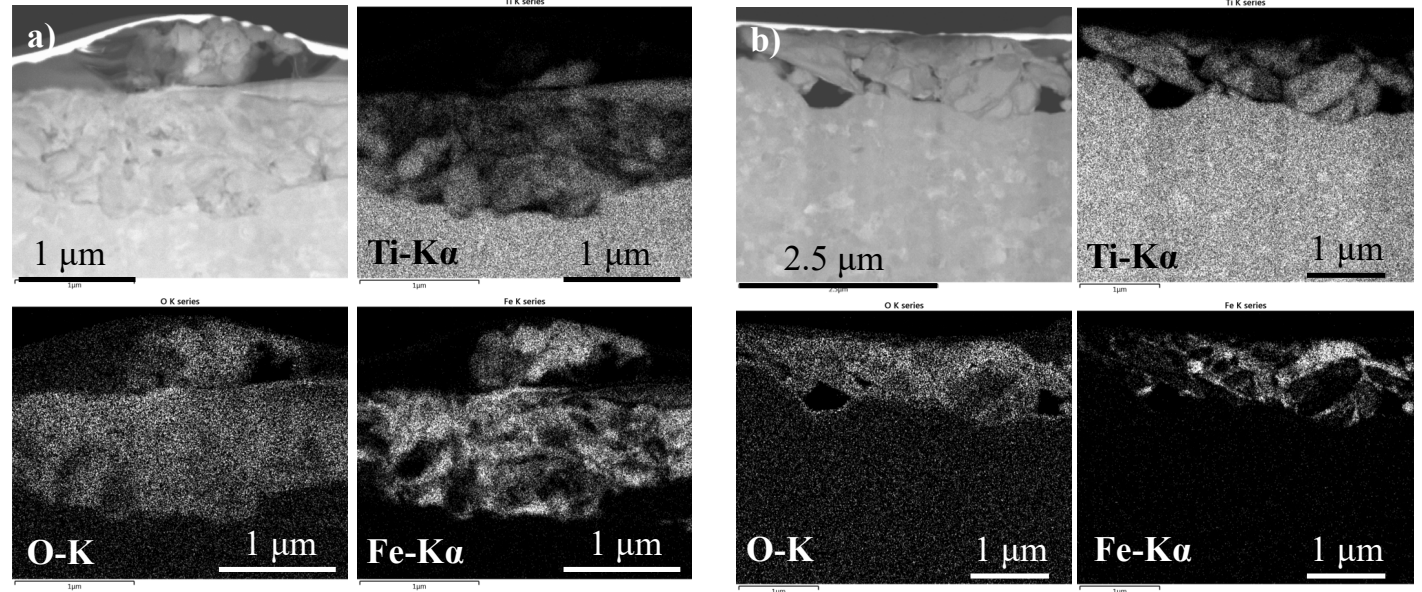

Figure 20 a) and b) present two groups of figures corresponding to DF images and Ti$\mathrm{K} \alpha, \mathrm{O}-\mathrm{K}$ and $\mathrm{Fe}-\mathrm{K} \alpha \mathrm{EDX}-\mathrm{STEM}$ maps acquired from two different regions of the top surface of the sample presented in Figure 19. 
Consequently, the decreasing effect of the COF with temperature could be explained in the light of the different MML structures. In the tests performed at RT, the MML structure appeared to lead to a lower COF, as compared to that measured during the tests at $450^{\circ} \mathrm{C}$. As it has been explained above, it is possible that the oxidation detected at the near surface of the worn samples tested at $450{ }^{\circ} \mathrm{C}$ has hardened the material and thus, the deformation by shear could have been restrained in these samples increasing the COF. On the other hand, the rise in temperature can also contribute to the increase of adhesion because the thermal diffusion is favoured [28]. This interpretation contrasts with that generally accepted theory in which the oxidation processes at high temperature results in a reduction of the $\mathrm{COF}$ between two metals because the oxides prevent the adhesion between them [28].

Finally, the differences found between the MML microstructures generated during the oscillating tests, as compared to the unidirectional sliding tests, could be associated to the different strain fields induced in the material by each movement. It should be mentioned that the results from the experiments conducted with different types of motion are not comparable. The oscillatory movement was near to fretting conditions and thus, the loss of debris form the contact is more difficult than in the case of unidirectional sliding movement tests [28]. It has been observed that similar wear mechanisms were occurring during the tests performed with both types of motion. However, the microstructural analysis of the worn samples revealed that the wear mechanisms were more severe when testing under unidirectional sliding conditions. For example, the unidirectional sliding movement appeared to produce a higher plastic deformation in the near surfaces and it has been shown that the samples had been subjected to more severe abrasive wear processes. This result has been concluded from the observation of fractured surfaces, cracks, thicker MMLs and larger debris particles. 
In addition, adhesive wear and delamination appeared to have a major role in the unidirectional sliding experiments leading to fractured surfaces and higher COF values. The more severe wear conditions might explain the marked difference observed in the order of magnitude of the COF and the wear rates between the oscillating and unidirectional sliding experiments.

\section{Conclusions}

This work was focused on the study of the application of CS Ti-6Al-4V coatings for repairing aeronautical Ti components. Two coatings have been tested which were sprayed with different process gas temperature and pressure: $800{ }^{\circ} \mathrm{C}$ and 40 bar (Ti64800 ), which are values widely used by researchers, and $1100^{\circ} \mathrm{C}$ and 50 bar (Ti641100). The samples were tested under unidirectional sliding and oscillating movements against a bearing steel counterbody with a pin on disc tribometer. The wear resistance of the coatings has been compared with that of the substrate, because the bulk Ti-6Al-4V is the material to be repaired. Therefore, the repairing coating needs to withstand wear equally well or even better than the substrate. The experiments have led to the following conclusions:

- The Ti64-800 coating presented a lower wear resistance, as compared to the Ti6Al-4V substrate material, under the applied wear conditions with unidirectional sliding as well as with oscillating movement. This result indicated that the wear resistance of this coating was poor and thus, it was not adequate for repairing proposes.

- The Ti64-1100 coating, which presented a higher hardness and lower porosity, was shown to fail under the unidirectional sliding movement but its wear resistance was shown to be comparable or even better to that of the substrate 
under oscillating movement. However, a further study is needed to prove this coating through a wider range of testing parameters in order to test its suitability for aeronautical repairs.

- The operating wear mechanisms were shown to be similar for all the studied materials, but they were shown to differ for different testing conditions, as it was reflected by the COF differences.

- The wear mechanisms associated to the different wear conditions were shown to be strongly related to the MML microstructure. The variability of the wear response of the samples was shown to be accompanied by changes in the MML microstructure which revealed the action of the different wear mechanisms.

- Abrasive and adhesive mechanisms were activated during the RT tests, and oxidative wear was also found in the samples tested at $450{ }^{\circ} \mathrm{C}$. The high temperature conditions led to higher COF and it was explained by the hardening of the near surfaces due to the formation of $\mathrm{Fe}$ and $\mathrm{Ti}$ oxides and to an increase in the adhesive contribution to wear. However, the MMLs microstructural changes explained the different wear rates: while the oxides provided a protective effect against wear in the unidirectional sliding tests, the wear resistance was lowered in the high temperature oscillating tests.

- The wear process was shown to be more severe during the unidirectional sliding tests showing a greater contribution of all the wear mechanisms. The wear rates were significantly greater as compared to the ones tested under oscillating conditions.

\section{Acknowledgements}

This work has received funding from the European Union's Seventh Framework Programme under grant agreements ACS3-GA-2013-605207 (CORSAIR) and 312483 - 
ESTEEM2 (Integrated Infrastructure Initiative-I3). The authors would also like to thank the financial support from the Spanish government CICYT under grants MAT201341784-R (REMACOLDS) and MAT2016-76928-C2-2-R (DURESPRAY).

Declarations of interests: None

\section{References:}

[1] M. Peters, J. Kumpfert, C.H. Ward, C. Leyens, Titanium alloys for aerospace applications, Adv. Eng. Mater. 5 (2003) 419-427.

[2] C. Leyens, M. Peters, Titanium an Titanium Alloys, 2003.

[3] A. Mouritz, Introduction to Aerospace Materials, 1st ed., Woodhead Publishing, Cambridge, 2012.

[4] S. Zhang, D. Zhao, eds., Aerospace Materials Handbook, 1st ed., CRC Press, New York, 2013.

[5] J. Villafuerte, ed., Modern Cold Spray: Materials, Process, and Applications, 1st ed., Springer, 2015.

[6] V.K. Champagne, The Cold Spray Materials Deposition Process: Fundamentals and Applications, 1st ed., Woodhead Publishing, 2007.

[7] L. Pawłowski, The Science and Engineering of Thermal Spray Coatings, 2nd ed., John Wiley \& Sons, The Atrium, 1995.

[8] A. Molinari, G. Straffelini, B. Tesi, T. Bacci, Dry sliding wear mechanisms of the Ti6Al4V alloy, Wear. 208 (1997) 105-112.

[9] K.G. Budinski, Tribological properties of titanium alloys, Wear. 151 (1991) 203217. 
[10] G. Straffelini, A. Molinari, Dry sliding wear of Ti-6Al-4V alloy as influenced by the counterface and sliding conditions, Wear. 236 (1999) 328-338.

[11] X. Jin, P.H. Shipway, W. Sun, The role of frictional power dissipation (as a function of frequency) and test temperature on contact temperature and the subsequent wear behaviour in a stainless steel contact in fretting, Wear. 330-331 (2015) 103-111.

[12] X.X. Li, Q.Y. Zhang, Y. Zhou, J.Q. Liu, K.M. Chen, S.Q. Wang, Mild and Severe Wear of Titanium Alloys, Tribol. Lett. 61 (2016) 1-9.

[13] X.H. Cui, Y.S. Mao, M.X. Wei, S.Q. Wang, Wear Characteristics of Ti-6Al-4V Alloy at $20-400^{\circ} \mathrm{C}$, Tribol. Trans. 55 (2012) 185-190.

[14] N.W. Khun, A.W.Y. Tan, E. Liu, Mechanical and Tribological Properties of Cold-Sprayed Ti Coatings on Ti-6Al-4V Substrates, J. Therm. Spray Technol. 25 (2016) 715-724.

[15] S.A. Alidokht, V.N.V. Munagala, R.R. Chromik, Role of Third Bodies in Friction and Wear of Cold-Sprayed Ti and Ti-TiC Composite Coatings, Tribol. Lett. 65 (2017) 1-15.

[16] A. Astarita, F. Rubino, P. Carlone, A. Ruggiero, C. Leone, S. Genna, M. Merola, A. Squillace, On the Improvement of AA2024 Wear Properties through the Deposition of a Cold-Sprayed Titanium Coating, Metals (Basel). 6 (2016) 1-12.

[17] P. Poza, P. Sirvent, Á. Rico, C.J. Múnez, M.Á. Garrido, Oscillating contact wear in cold sprayed ti6al4v coatings for aeronautical repairs, in: Mater. Sci. Forum, Trans Tech Publications Ltd, 2018: pp. 1686-1691. 
[18] N.W. Khun, A.W.Y. Tan, W. Sun, E. Liu, Wear and Corrosion Resistance of Thick Ti-6Al-4V Coating Deposited on Ti-6Al-4V Substrate via High-Pressure Cold Spray, J. Therm. Spray Technol. 26 (2017) 1393-1407.

[19] M.A. Garrido, P. Sirvent, P. Poza, Evaluation of mechanical properties of Ti6Al4V cold sprayed coatings, Surf. Eng. 34 (2017) 399-405.

[20] ASTM G99-17, Standard Test Method for Wear Testing with a Pin-on- Disk Apparatus, West Conshohocken, PA, 2017.

[21] R.C. Bill, Selected Fretting Wear Resistant Coatings for Ti6Al4V alloy, 1976.

[22] R.C. Bill, Fretting of Titanium at Temperatures to $650^{\circ} \mathrm{C}, 2017$.

[23] I. Hutchings, Tribology: Friction and Wear of Engineering Materials, 1st ed., Butterworth-Heinemann, 1992.

[24] D.A. Rigney, L.H. Chen, M.G.S. Naylor, A.R. Rosenfield, Wear processes in sliding systems, Wear. 100 (1984) 195-219.

[25] X.X. Li, Y. Zhou, X.L. Ji, Y.X. Li, S.Q. Wang, Effects of sliding velocity on tribo-oxides and wear behavior of Ti-6Al-4V alloy, Tribol. Int. 91 (2015) 228234.

[26] M.J. Donachie, Titanium: A Technical Guide, 2nd ed., ASM International, 2000.

[27] C.H. Hager, J.H. Sanders, S. Sharma, Effect of high temperature on the characterization of fretting wear regimes at Ti6Al4V interfaces, Wear. 260 (2006) 493-508.

[28] I. Hutchings, P. Shipway, Tribology: Friction and Wear of Engineering Materials, 2nd ed., Elsevier Ltd, Oxford, 2017. 
